\title{
Cell wall remodeling under salt stress: Insights into changes in polysaccharides, feruloylation, lignification, and phenolic metabolism in maize
}

Dyoni M. Oliveira ${ }^{1 *}$, Thatiane R. Mota ${ }^{1}$, Fábio V. Salatta ${ }^{1}$, Renata C. Sinzker ${ }^{1}$, Radka Končitíková2 ${ }^{2}$ David Kopečný2, Rachael Simister ${ }^{3}$, Mariana Silva ${ }^{3}$, Geert Goeminne ${ }^{4,5}$, Kris Morreel $^{4,5}$, Jorge Rencoret ${ }^{6}$, Ana Gutiérrez ${ }^{6}$, Theodora Tryfona ${ }^{7}$, Rogério Marchiosi ${ }^{1}$, Paul Dupree $^{7}$, José C. del Río ${ }^{6}$, Wout Boerjan ${ }^{4,5}$, Simon J. McQueen-Mason³, Leonardo D. Gomez ${ }^{3}$, Osvaldo Ferrarese-Filho ${ }^{1}$, Wanderley D. dos Santos ${ }^{1 *}$

${ }^{1}$ Department of Biochemistry, State University of Maringá, Maringá, Brazil

2 Department of Protein Biochemistry and Proteomics, Centre of the Region Haná for Biotechnological and Agricultural Research, Faculty of Science, Palacký University, Olomouc, Czech Republic

${ }^{3}$ Centre for Novel Agricultural Products, Department of Biology, University of York, York, United Kingdom

${ }^{4}$ Department of Plant Biotechnology and Bioinformatics, Ghent University, Ghent, Belgium

${ }^{5}$ Center for Plant Systems Biology, VIB, Ghent, Belgium

${ }^{6}$ Instituto de Recursos Naturales y Agrobiología de Sevilla, CSIC, Seville, Spain

${ }^{7}$ Department of Biochemistry, University of Cambridge, Cambridge, United Kingdom

\section{*Corresponding authors}

This article has been accepted for publication and undergone full peer review but has not been through the copyediting, typesetting, pagination and proofreading process which may lead to differences between this version and the Version of Record. Please cite this article as doi: $10.1111 /$ pce. 13805 
Dyoni M. Oliveira (dyonioliveira@gmail.com) and Wanderley D. dos Santos (wdsantos@uem.br)

Running Head: Cell wall changes upon salinity

\section{ABSTRACT}

Although cell wall polymers play important roles in the tolerance of plants to abiotic stress, the effects of salinity on cell wall composition and metabolism in grasses remain largely unexplored. Here, we conducted an in-depth study of changes in cell wall composition and phenolic metabolism induced upon salinity in maize seedlings and plants. Cell wall characterization revealed that salt stress modulated the deposition of cellulose, matrix polysaccharides and lignin in seedling roots, plant roots and stems. The extraction and analysis of arabinoxylans by size-exclusion chromatography, 2D-NMR spectroscopy and carbohydrate gel electrophoresis showed a reduction of arabinoxylan content in salt-stressed roots. Saponification and mild acid hydrolysis revealed that salinity also reduced the feruloylation of arabinoxylans in roots of seedlings and plants. Determination of lignin content and composition by nitrobenzene oxidation and 2D-NMR confirmed the increased incorporation of syringyl units in lignin of maize roots. Salt stress also induced the expression of genes and the activity of enzymes enrolled in phenylpropanoid biosynthesis. The UHPLC-MS-based metabolite profiling confirmed the modulation of phenolic profiling by salinity and the accumulation of ferulate and its derivatives 3- and 4-O-feruloyl quinate. In conclusion, we present a model for explaining cell wall remodeling in response to salinity. 
Keywords: Abiotic stress, cell wall, ferulic acid, lignification, $p$-coumaric acid, salinity, xylan, Zea mays. 


\section{1 | INTRODUCTION}

Soil salinity is an important environmental problem for more than 800 million hectares of land (ca. 6\% of the world's total land), which are affected by either salinity (397 million ha) or sodicity (434 million ha) (Munns and Tester, 2008). Salt stress results in osmotic stress, ionic imbalances, ion toxicity, oxidative damage and complex effects on the physiology and metabolism of the plant (Negrão et al., 2017). The growth of most cereal crops is reduced when the soil salinity exceeds $4 \mathrm{dS} / \mathrm{m}$ of electrical conductivity, which is equivalent to $40 \mathrm{mM}$ sodium chloride (Munns and Tester, 2008; Munns et al., 2019). Maize (Zea mays L.) is the crop with the highest global annual grain yield and presents biochemical and physiological adaptations that allow it to grow when exposed to salt concentrations up to $200 \mathrm{mM}$ sodium chloride (Farooq et al., 2015).

Plant cell walls are highly dynamic and responsive structures that can be remodelled during plant growth, development and in response to various abiotic and biotic stresses (Tenhaken, 2014; Le Gall et al., 2015; Voiniciuc et al., 2018; Cesarino, 2019; Gladala-Kostarz et al., 2020). The complex arrangement of cell wall polymers provides mechanical and structural integrity to each cell, sustains differential growth during cell division and expansion, and serves as a sensory interface between the plant and its environment (Burton et al., 2010; Vaahtera et al., 2019). The tolerance of plants to salinity is closely related to the formation of secondary cell walls and the deposition pattern of cellulose and lignin (Wang et al., 2016; Byrt et al., 2018). Most of the studies on cell wall modifications induced upon abiotic stress have primarily focused on genes and proteins putatively involved in cell wall metabolism. However, much less 
is known on the structural alterations of the different cell wall polymers that are provoked by salt stress (Tenhaken, 2014; Le Gall et al., 2015; Rui and Dinneny, 2019).

Cellulose is the main component of plant cell walls. This macromolecule consists of unbranched and unsubstituted $\beta$-(1,4)-D-linked glucan chains that form non-covalent microfibrillar complexes through extensive intra and intermolecular hydrogen bonding and hydrophobic interactions (Burton et al., 2010). Exposure to salinity directly or indirectly modulates cellulose biosynthesis by regulating cellulose synthase genes and the arrangement of cellulose microfibrils (Endler et al., 2015; Wang et al., 2016; Kesten et al., 2019).

Lignin impregnates the secondary cell walls of vascular plants, providing mechanical support, impermeability and resistance to biodegradation (Moura et al., 2010; Mota et al., 2019; Ralph et al., 2019). Lignin is synthesized via the phenylpropanoid pathway followed by oxidative radical coupling of lignin monomers. The main canonical monolignols, $p$-coumaryl, coniferyl and sinapyl alcohols, constitute the p-hydroxyphenyl (H), guaiacyl (G), and syringyl (S) units in the lignin polymer, respectively (Ralph et al., 2004; Vanholme et al., 2010). Additional monomers are also incorporated into lignin polymer. For example, grasses incorporate $\gamma-p$ coumaroylated monolignols during lignification, producing $\gamma$-acylated lignin units (Ralph, 2010; Petrik et al., 2014). Notably, abiotic stress can rapidly induce the biosynthesis and deposition of lignin in secondary cell walls (Moura et al., 2010; Cesarino, 2019; Vanholme et al., 2019).

Ferulic (FA) and p-coumaric acid ( $p$ CA) are also produced by the phenylpropanoid pathway. Activated with Coenzyme A (CoA) as feruloyl-CoA and p-coumaroyl-CoA, they are 
intermediary metabolites toward the formation of monolignols and precursors for the acylation of xylan and lignin (Hatfield et al., 2009; Ralph, 2010; Hatfield et al., 2017). Xylan is the main hemicellulose of grasses and its backbone consists of a linear chain of $\beta$-(1,4)-D-linked xylopyranosyl residues (Xylp) (Rennie and Scheller, 2014). Arabinofuranosyl residues (Araf) are $\alpha$-(1,2)- or $\alpha$-(1,3)-linked to the xylan chain assembling the arabinoxylan (AX), which may be further esterified with FA (and $p$ CA at lower levels) at the $O-5$ position of Araf residues. Feruloylation of AX may act to cross-link AX chains to each other or to lignins, resulting in a highly recalcitrant lignin-hydroxycinnamate-carbohydrate complex (Grabber et al., 2000; de Oliveira et al., 2015; Hatfield et al., 2017; Oliveira et al., 2020).

Little is known about the chemical nature and particularly the structural features underlying cell wall compositional shifts in response to abiotic stresses (Tenhaken, 2014; Le Gall et al., 2015; Cesarino, 2019; Zhao et al., 2019). During recent years, our understanding of cell wall biosynthesis and structure has improved profoundly, for instance, the feruloylation and $p$ coumaroylation of AX (Bartley et al., 2013; Buanafina et al., 2016; de Souza et al., 2018; de Souza et al., 2019), lignin acylation (Withers et al., 2012; Petrik et al., 2014; Wilkerson et al., 2014; Karlen et al., 2016; Karlen et al., 2018), xylan biosynthesis and structure (Anders et al., 2012; Grantham et al., 2017; Whitehead et al., 2018; Tryfona et al., 2019), and covalent interactions between lignin, xylan and cellulose (Busse-Wicher et al., 2016; Simmons et al., 2016; Kang et al., 2019). Based on these new findings, we examined how salt stress affects the cell wall composition of maize seedlings and plants. Using state-of-the-art analytical tools, we examined the amount and composition of the cell wall polysaccharides and lignin, determined the extent of cell wall feruloylation, evaluated the expression of genes and the activity of 
enzymes involved in FA biosynthesis, and compared the abundance of phenolic metabolites differentially produced upon salinity. Our data revealed that maize copes with the saline environment by remodeling its cell wall composition and phenolic metabolism, by reducing the degree of feruloylation of AX and by altering lignin monomeric composition

\section{2 | MATERIALS AND METHODS}

\section{1 | Plant material and growth conditions}

Maize (Zea mays L. cv. IPR-164) seeds were surface sterilized with $2 \% \mathrm{NaClO}$ and germinated at $25{ }^{\circ} \mathrm{C}$ on moistened filter paper under dark conditions. For the experiments with seedlings, 25 seedlings of 3-day-old with uniform growth were transferred to hydroponic nutrient solution (Dong et al., 2006) supplemented with different $\mathrm{NaCl}$ concentrations (0 to $200 \mathrm{mM}$ ), and grown for three days at $25{ }^{\circ} \mathrm{C}$ under a $12 \mathrm{~h}$ photoperiod. The initial screening with different concentrations of $\mathrm{NaCl}$ showed that $200 \mathrm{mM} \mathrm{NaCl}$ changed simultaneously the amounts of cell wall-bound FA, pCA and lignification in seedling roots (Fig. S1). Based on this screening, 200 $\mathrm{mM} \mathrm{NaCl}$ was selected for subsequent experiments in seedlings. For the experiments with maize plants, 2-day-old seedlings were transferred to 500-ml pots with $400 \mathrm{~g}$ of vermiculite and grown at $25^{\circ} \mathrm{C}$ under a photoperiod of $12 \mathrm{~h}$. After the fifth day, the plants were watered every two days with $60 \mathrm{ml}$ nutrient solution (full substrate capacity) in the absence (control) or presence of $\mathrm{NaCl}$. The concentration was selected based on the initial screening in plants 
exposed upon different $\mathrm{NaCl}$ concentrations (0 to $200 \mathrm{mM}$ ), using lignin amount as the measure (Fig. S2). Similarly to seedlings, $200 \mathrm{mM} \mathrm{NaCl}$ increased lignin content in roots and stems, thereupon this concentration was employed for subsequent experiments. After 17 days of cultivation, the roots, stems and leaves without sheaths were harvested and used for the experiments.

Plant growth parameters were obtained at the end of the cultivation of seedlings and plants. The lengths and fresh weights of roots, stems and leaves were measured immediately after harvesting, whereas the dry weights were determined after drying the plant material in an oven at $60{ }^{\circ} \mathrm{C}$ for three days. Relative water content (RWC) was calculated as follow: $\mathrm{RWC} \%=$ (Fresh weight - Dry weight)/Fresh weight $\times 100$. Thiobarbituric acid reactive substances (TBARS) content was determined as detailed in Methods S1. The schematic flowchart summarizing the experimental design and the methodologies applied in this study is shown in Fig. S3.

\section{2 | Alcohol insoluble residue preparation}

A total of $200 \mathrm{mg}$ of milled material was incubated in $5 \mathrm{ml}$ of phenol for $30 \mathrm{~min}$ at room temperature under agitation, followed by centrifugation at 3,000×g for $20 \mathrm{~min}$. The supernatant was removed and the pellet was washed twice with chloroform:methanol (2:1, v/v) and once with absolute ethanol. After centrifugation, the pellet was incubated over-night with $90 \%$ aqueous dimethyl sulfoxide $(v / v)$ at room temperature under agitation, followed by centrifugation and washed thrice with absolute ethanol. The pellets were dried at $45{ }^{\circ} \mathrm{C}$ and considered as the alcohol insoluble residue (AIR). 


\section{3 | ATR-FTIR spectroscopy}

Attenuated Total Reflectance-Fourier Transform Infrared (ATR-FTIR) spectra of AIR samples were obtained between $850-1850 \mathrm{~cm}^{-1}$ using a Spectrum One spectrometer (Perkin-Elmer) as previously reported (Marriott et al., 2014). Spectral assignments were made according to the literature (Table S1).

\section{4 | Matrix monosaccharide composition and crystalline cellulose content}

The AIR (4 mg) was hydrolyzed with $500 \mu \mathrm{l}$ of $2 \mathrm{M}$ trifluoroacetic acid (TFA) at $100{ }^{\circ} \mathrm{C}$ for 4 h, under oxygen-free condition. Following the evaporation under vacuum for the removal of TFA, the samples were rinsed twice with isopropanol and resuspended in $200 \mu \mathrm{l}$ of water. Samples were filtered with $0.45 \mu \mathrm{m}$ polytetrafluoroethylene filters and analyzed by highperformance anion-exchange chromatography with pulsed amperometric detection (HPAECPAD) (Carbopac PA10 column; Dionex ICS3000 system, Camberley, UK) (Jones et al., 2003). The residue following $2 \mathrm{M}$ TFA hydrolysis was used for the determination of crystalline cellulose content using the anthrone-sulfuric acid method as previously described by Foster et al. (2010) with modifications (see Methods S1 for a detailed description).

\section{5 | Sequential extraction and analysis of xylan}

For xylan extraction, the AIR was firstly destarched as described by Whitehead and coworkers (2018). Next, the sequential extraction of xylan was performed by agitating $20 \mathrm{mg}$ of destarched AIR in $2 \mathrm{ml}$ of $50 \mathrm{mM}$ 1,2-cyclohexylenedinitrilotetraacetic acid (CDTA) (pH 6.5) for $24 \mathrm{~h}$ at room temperature. The suspension was centrifuged $\left(14,000 \times g, 4^{\circ} \mathrm{C}\right.$ for $\left.10 \mathrm{~min}\right)$ and the pellet 
washed once with deionized water. The pellets were subsequently extracted under oxygen-free conditions using $50 \mathrm{mM} \mathrm{Na}_{2} \mathrm{CO}_{3}$ containing $10 \mathrm{mM} \mathrm{NaBH}_{4}$ for $24 \mathrm{~h}$ at $4{ }^{\circ} \mathrm{C}, 1 \mathrm{M} \mathrm{KOH}$ with 10 $\mathrm{mM} \mathrm{NaBH} 4$ for $24 \mathrm{~h}$ at $4{ }^{\circ} \mathrm{C}$ and $4 \mathrm{M} \mathrm{KOH}$ with $10 \mathrm{mM} \mathrm{NaBH}_{4}$ for $24 \mathrm{~h}$ at $4{ }^{\circ} \mathrm{C}$. The $\mathrm{KOH}-$ soluble fractions were adjusted to $\mathrm{pH} 5$ with $100 \mu \mathrm{l}$ of glacial acetic acid, dialyzed extensively against deionized water for $24 \mathrm{~h}$ at $4{ }^{\circ} \mathrm{C}$ and freeze-dried. For the monosaccharide analysis, $1 \mathrm{mg}$ of freeze-dried $\mathrm{KOH}$ fraction was hydrolyzed with $2 \mathrm{M}$ TFA followed by HPAEC-PAD analysis.

\subsection{Xylan analysis by size-exclusion chromatography coupled to multi-angle light- scattering (SEC-MALS)}

The analysis of the molecular weight of the xylan was conducted using size-exclusion chromatography (SEC) method described by Brown and coworkers (2009) with minor modifications (Whitehead et al., 2018). The 1 and $4 \mathrm{M} \mathrm{KOH}$ fractions (1 mg) were suspended in $1 \mathrm{ml}$ of $50 \mathrm{mM}$ sodium acetate and filtered with $0.2 \mu \mathrm{m}$ polytetrafluoroethylene filters. The fractions were separated by SEC (Superdex S200 10/300 GL \#0805015, G.E. Healthcare), followed by analyses with Wyatt HELEOS-II multi-angle light-scattering (MALS) detector and a Wyatt rEX refractive index detector system linked to a Shimadzu HPLC system (SPD-20A UV detector, LC20-AD isocratic pump system, DGU-20A3 degasser and SIL-20A autosampler). Data were analysed using the Astra V software. A value of 0.145 was used for sample refractive index increment (dn/dc).

2.7 Enzymatic hydrolysis of xylan and polysaccharide analysis by carbohydrate gel electrophoresis (PACE) 
The enzymatic hydrolysis of destarched AIR of seedling roots and plant roots, derivatization of released oligosaccharides, carbohydrate electrophoresis, PACE gel scanning and quantification was performed as described by Goubet et al. (2002) and Goubet et al. (2009) (see Methods S1 for a detailed description). The enzymes used for xylan digestion were: GH10 endo- $\beta-1,4-$ xylanase from Cellvibrio japonicus (CjGH10A); GH11 endo- $\beta-1,4-x y l a n a s e$ from Neocallimastix patriciarum (NpGH11A); GH62 $\alpha$-arabinofuranosidase from Penicillium aurantiogriseum (PaGH62) and GH115 $\alpha$-glucuronidase from Bacteroides ovatus (BoGH115).

\section{8 | Determination of total cell wall ester-linked hydroxycinnamates}

To release esterified hydroxycinnamic acids from the cell walls, $700 \mu 1$ of $2 \mathrm{M} \mathrm{NaOH}$ was added to $10 \mathrm{mg}$ of AIR and incubated at $25^{\circ} \mathrm{C}$ for $16 \mathrm{~h}$. After addition of $200 \mu \mathrm{l}$ of $10 \mathrm{M} \mathrm{HCl}$, phenolics were partitioned three times with anhydrous ethyl ether and dried. The residue after evaporation was dissolved in acetonitrile $50 \%(v / v)$ and filtered through a $0.45 \mu \mathrm{m}$ filter. Quantification of hydroxycinnamic acids was carried out on a HPLC system (Shimadzu ${ }^{\circledR}$, Tokyo, Japan) with SPD-10A UV-VIS detector. The compounds were separated at $35^{\circ} \mathrm{C}$ on a C18 column $\left(150 \times 4.6 \mathrm{~mm}, 5 \mu \mathrm{m}\right.$; Supelco Discovery $\left.{ }^{\circledR}\right)$. The mobile phase was acetonitrile $90 \% /$ formic acid $0.1 \%(20 / 80, v / v)$ with a flow rate of $1.0 \mathrm{ml} / \mathrm{min}$ in isocratic mode. The identities and quantities of the separated molecules were confirmed based on the UV signatures at $322 \mathrm{~nm}$ for FA and $309 \mathrm{~nm}$ for $p$ CA, obtained in comparison with the respective standards.

\section{9 | Determination of hydroxycinnamate conjugates released by mild acidolysis}


AIR (10 mg) was hydrolyzed with $1 \mathrm{ml}$ of $50 \mathrm{mM}$ TFA and incubated at $99{ }^{\circ} \mathrm{C}$ for $4 \mathrm{~h}$ as described by Bartley et al. (2013) and de Souza et al. (2018) with modifications. After centrifugation for $10 \mathrm{~min}$ at $10,000 \times g, 400 \mu \mathrm{l}$ of TFA-supernatant was freeze-dried. The pellet was washed twice with water and acetone, and left to dry at $45^{\circ} \mathrm{C}$. Next, dried pellets and TFAextracts were saponified with $700 \mu \mathrm{l}$ of $2 \mathrm{M} \mathrm{NaOH}$ at $25{ }^{\circ} \mathrm{C}$ for $16 \mathrm{~h}$. After acidification with $200 \mu \mathrm{l}$ of $10 \mathrm{M} \mathrm{HCl}$, phenolics were partitioned three times with anhydrous ethyl ether and dried. The residue after evaporation was resuspended in acetonitrile 50\% $(v / v)$ and filtered through a $0.45 \mu \mathrm{m}$ filter for HPLC analysis. Released FA and pCA from the TFA-soluble fractions are esterified to AX and those released from the pellets are esterified to lignin fraction.

\subsection{0 | Quantitative real-time PCR}

RNA was isolated from maize tissues using the RNAqueous kit (Ambion) and treated twice with a Turbo DNase-free kit (Ambion) (see Methods S1 for a detailed description). Gene identifiers, probes and primer pairs are given in Table S2.

\subsection{1 | Enzymatic assays}

For all the enzymatic assays, fresh tissues ( $1 \mathrm{~g}$ ) were ground using ice-cooled pestle and mortar with $1.5 \mathrm{ml}$ of extraction buffer (as indicated for each enzyme) for $3 \mathrm{~min}$. After centrifugation $\left(10,000 \times g, 15 \mathrm{~min}, 4^{\circ} \mathrm{C}\right)$, the supernatant was collected and used for the enzymatic assay. The activities were expressed as nmol product $\min ^{-1} \mathrm{mg}^{-1}$ of fresh weight. Control experiments without substrates were performed under the same conditions to identify any endogenous compounds in the enzymatic extracts. 
p-Hydroxycinnamate-CoA ligase (4CL) activity was carried out as described by Bevilaqua et al. (2019), using p-coumaric acid or ferulic acid as substrates. The extraction buffer contained $200 \mathrm{mM}$ Tris- $\mathrm{HCl}$ (pH 7.5), $10 \mathrm{mM} \mathrm{MgCl}, 5 \mathrm{mM}$ DTT and 20\% glycerol $(v / v)$. The reaction mixture contained 200 mM Tris-HCl (pH 7.2), 10 mM MgCl, 5 mM DTT, 4 mM ATP, $100 \mu l$ of protein extract, $0.4 \mathrm{mM}$ p-coumaric acid or ferulic acid, and $0.2 \mathrm{mM}$ Coenzyme A (CoA) to initiate the reaction. After the addition of CoA, the reaction was incubated at $35{ }^{\circ} \mathrm{C}$ for $10 \mathrm{~min}$. The increase in absorbance at $333 \mathrm{~nm}$ for $p$-coumaroyl-CoA and $346 \mathrm{~nm}$ for feruloyl-CoA were spectrophotometrically monitored.

Hydroxycinnamaldehyde dehydrogenase (HCALDH) activity was carried out as described by Nair et al. (2004) and Ferro et al. (2020). The extraction buffer for HCALDH activity contained $50 \mathrm{mM}$ Hepes-HCl (pH 8.0), $5 \mathrm{mM}$ DTT, $1 \mathrm{mM}$ EDTA and 10\% glycerol $(v / v)$. After precipitation with $70 \%$ saturated ammonium sulfate, the pellet was homogenized in extraction buffer and used as the enzyme extract. The reaction mixture contained $50 \mathrm{mM}$ Hepes- $\mathrm{HCl}$ (pH 8.0), $5 \mathrm{mM}$ DTT, $1 \mathrm{mM} \mathrm{NAD}{ }^{+}, 100 \mu \mathrm{l}$ of enzyme extract, $100 \mu \mathrm{M}$ coniferaldehyde (to initiate the reaction), and was incubated for $10 \mathrm{~min}$ at $40{ }^{\circ} \mathrm{C}$. The reaction was terminated with the addition of $3 \mathrm{M} \mathrm{HCl}$. After centrifugation (10,000×g, $2 \mathrm{~min}$ ), the samples were filtered through a $0.45 \mu \mathrm{m}$ filter and submitted to HPLC analysis, following the same experimental conditions for the quantification of ester-linked hydroxycinnamates.

Caffeic acid 3-O-methyltransferase (COMT) activity was performed as described by Bevilaqua et al. (2019). The extraction buffer contained $100 \mathrm{mM}$ Tris- $\mathrm{HCl}(\mathrm{pH} 7.2), 0.2 \mathrm{mM} \mathrm{MgCl}, 2$ $\mathrm{mM}$ DTT and 10\% glycerol $(v / v)$. The reaction mixture contained $100 \mathrm{mM}$ Tris- $\mathrm{HCl}(\mathrm{pH}$ 7.2), 
$0.2 \mathrm{mM} \mathrm{MgCl}_{2}, 2 \mathrm{mM}$ DTT, 1 mM S-adenosyl-L-methionine, $200 \mu \mathrm{l}$ of enzyme extract, $60 \mu \mathrm{M}$ caffeic acid (to initiate the reaction), and was incubated for $30 \mathrm{~min}$ at $30{ }^{\circ} \mathrm{C}$. The reaction was terminated by the addition of $3 \mathrm{M} \mathrm{HCl}$. After centrifugation $(10,000 \times g$, $2 \mathrm{~min})$, the samples were filtered through a $0.45 \mu \mathrm{m}$ filter and submitted to HPLC analysis, following the same experimental conditions for the quantification of ester-linked hydroxycinnamates.

For the activity of feruloyl esterase (FAE), the extraction was carried out in $100 \mathrm{mM}$ 2-(Nmorpholino) ethanesulfonic acid (MES) $\mathrm{pH}$ 6.0, $10 \%$ glycerol $(v / v)$ and $0.2 \mathrm{~g}$ polyvinylpolypyrrolidone. The reaction mixture contained $100 \mathrm{mM}$ MES (pH 6.0), $100 \mu \mathrm{l}$ of enzyme extract, $100 \mu \mathrm{M}$ methyl ferulate (to initiate the reaction), and was incubated for $30 \mathrm{~min}$ at $35{ }^{\circ} \mathrm{C}$. The reaction was terminated by boiling for $3 \mathrm{~min}$ at $100{ }^{\circ} \mathrm{C}$. After centrifugation $(10,000 \times g, 2 \mathrm{~min})$, the samples were filtered through a $0.45 \mu \mathrm{m}$ filter and submitted to HPLC analysis.

\subsection{2 | Metabolic profiling}

Fresh roots of seedlings and plants ( $\sim \mathrm{mg}$ dry weight per sample) were homogenized in liquid nitrogen and extracted with $500 \mu \mathrm{l}$ of methanol for $15 \mathrm{~min}$ at $70{ }^{\circ} \mathrm{C}$. The methanol extract was then evaporated and the pellet dissolved in $200 \mu \mathrm{l}$ water/cyclohexane $(1 / 1, v / v) .10 \mu 1$ of the aqueous phase was analyzed via reverse-phase Ultra High Performance Liquid Chromatography (UHPLC; Acquity UPLC Class 1 system consisting of a Sample ManagerFTN, a Binary Solvent Manager and a Column Manager, Waters Corporation, Milford, MA) coupled to negative ion ElectroSpray Ionization-Quadrupole-Time-of-Flight Mass Spectrometry (ESI-Q-ToF-MS; Vion IMS Q-Tof, Waters Corporation) using an Acquity UPLC 
BEH C18 column $(2.1 \mathrm{~mm} \times 150 \mathrm{~mm}, 1.7 \mu \mathrm{m}$, Waters Corporation $)$. Using a flow rate of 350 $\mu \mathrm{l} / \mathrm{min}$, a linear gradient was run from $95 \%$ aqueous formic acid $(0.1 \%$, buffer $\mathrm{A})$ to $50 \%$ acetonitrile $(0.1 \%$ formic acid, buffer $\mathrm{B})$ in $30 \mathrm{~min}$, followed by a concave gradient (curve 3) in 10 min to $100 \%$ buffer B. Full MS spectra $(\mathrm{m} / \mathrm{z} 50-\mathrm{m} / \mathrm{z}$ 1,500) were recorded at a scan rate of $10 \mathrm{~Hz}$.

Integration and alignment of the $\mathrm{m} / \mathrm{z}$ features were performed via Progenesis QI software version 2.1 (Waters Corporation). Peak picking was based on all runs with a sensitivity set on 'automatic' (value $=5$ ). The normalization was set on 'external standards' and was based on the dry weight of the samples (Morreel et al., 2006). The precursor ion search (10 ppm tolerance) was based on a compound database constructed via instant JChem (ChemAxon, Hungary), whereas MS/MS identities were obtained by matching against an in-house mass spectral database (200 ppm fragment tolerance). Using R vs 3.4.2., $\mathrm{m} / \mathrm{z}$ features representing the same compound were grouped following the algorithm described by Morreel and coworkers (2014). Abundance values that were lower than the detection threshold, and 'NA's were replaced randomly by either 1 or 2 . Differential $\mathrm{m} / \mathrm{z}$ features were defined as those for which the abundance was (i) significantly different and (ii) at least two-fold changed between control and salt-stressed plants.

\subsection{3 | Determination of lignin content and composition}

Lignin content was determined by the acetyl bromide method and the monomeric composition was assessed using alkaline nitrobenzene oxidation as described by Moreira-Vilar et al. (2014) with modifications (see Methods S1 for a detailed description). 


\subsection{4 | Cell wall characterization by two-dimensional NMR}

The whole-cell walls of maize tissues were characterized using two-dimensional heteronuclear single-quantum coherence NMR (2D-HSQC-NMR) at solution state as previously described (Kim et al., 2008; Rencoret et al., 2009) (see Methods S1 for a detailed description). 2DHSQC-NMR cross-signals were assigned by literature comparison (Fornalé et al., 2017; Kim et al., 2017). Assignments of the lignin and protein ${ }^{1} \mathrm{H} /{ }^{13} \mathrm{C}$ correlation signals in the 2D-HSQCNMR spectra from the whole cell walls are given in Table S3.

\subsection{5 | Statistical analysis}

In the experiments with maize seedlings, each biological replicate $(n)$ consisted of a bulk containing 25 seedlings, whereas in the experiments with maize plants, each biological replicate consisted of a bulk containing six plants. The two-sample Student's t-test (two-tailed distribution) was applied to compare control and salt-treated samples. Statistical significance was defined as $* 0.05 \geq P>0.01$, ** $0.01 \geq P>0.001$, and $* * * P \leq 0.001$.

\section{3 | RESULTS}

\section{1 | Salt stress induces changes in plant growth and cell wall polysaccharides}

To investigate the chemical nature and structural features of the cell walls of maize tissues exposed to salt stress, we cultivated seedlings for three days and plants for 12 days on control and $200 \mathrm{mM} \mathrm{NaCl}$ conditions. In seedlings, we studied the roots (S-roots) and in plants, we 
studied the roots, stems and leaves. The phenotypic response of seedlings and plants showed a significant restriction of the growth (Fig. 1a). Notably, salt stress promoted reductions in all the growth parameters (length, fresh biomass, dry biomass, and relative water content) in S-roots, and roots, stems and leaves of plants (Fig. S4). The amounts of thiobarbituric acid reactive substances (TBARS) significantly increased in all the salt-stressed tissues, suggesting oxidative damage caused by salt stress on maize tissues.

We then prepared the alcohol insoluble residue (AIR) and analyzed the cell wall composition using state-of-the-art analytical tools (see Fig. S3 for details). First, the AIR was subjected to Fourier transform infrared (FTIR) spectroscopy to verify the similarities in cell wall composition between the samples (Marriot et al., 2016). Principal component analysis (PCA) of the FTIR data showed a clear separation between spectra derived from control and $\mathrm{NaCl}$ treated samples, with S-roots exposed to salinity showing the most extreme separation (Fig. 1b). The corresponding loading plots show the contribution of each wavelength to the separation of the samples on each principal component (PC). The loading plots for PC1 and PC2 (Fig. 1c) revealed two large peaks at wavelengths corresponding to $\mathrm{C}-\mathrm{O}$ and $\mathrm{C}-\mathrm{O}-\mathrm{C}$ stretching assigned to cell wall polysaccharides $\left(950-1,100 \mathrm{~cm}^{-1}\right)$ and $\mathrm{C}=\mathrm{C}$ stretching and aromatic skeletal vibrations assigned to lignin $\left(1,510-1,630 \mathrm{~cm}^{-1}\right)$ (Oliveira et al., 2020).

The amount of crystalline cellulose measured by the anthrone-sulfuric acid method in AIR of plant roots and stems was significantly reduced ( $-11 \%$ and $-29 \%$, respectively) upon salt stress, while that of S-roots and leaves was similar to that of the corresponding controls (Fig. 1d). We also observed a reduction in matrix polysaccharide content of S-roots (-24\%) and roots of plants 
$(-18 \%)$ as compared to respective controls. Conversely, in leaves, the matrix polysaccharide content was increased by $18 \%$, whereas no significant differences were observed in matrix polysaccharide content in stems upon $\mathrm{NaCl}$ exposure.

Analysis of the matrix polysaccharide composition revealed that the major glycosyl residues were xylose (26-35\%), arabinose (17-20\%) and glucose (15-22\%) (Fig. S5). We found significant changes in the monosaccharide profiles in S-roots and plant roots in response to salinity. Fig. 1e, $\mathbf{f}$ shows a marked decrease of $18-24 \%$ in xylose and arabinose contents in Sroots and plant roots. In stems, neither xylose nor arabinose contents were altered by salt-stress, whilst in leaves only arabinose increased (11\%) (Fig. 1g, h). In addition, exposure to $\mathrm{NaCl}$ reduced the glucose content in S-roots (-39\%), whereas higher levels of glucose were observed in stems (22\%) and leaves (62\%). The abundance of several other monosaccharides, including galactose, fucose, mannose, rhamnose, glucuronic and galacturonic acids, which are derived from less abundant polysaccharides in maize cell walls, were also significantly altered by $\mathrm{NaCl}$ treatment.

\section{2 | Salt-stressed roots exhibit reduced arabinoxylan content}

To determine structural shifts in xylan of S-roots and plant roots, the destarched AIR was sequentially extracted with CDTA and $\mathrm{Na}_{2} \mathrm{CO}_{3}$ to remove pectins, followed by extraction with 1 and $4 \mathrm{M} \mathrm{KOH}$ to produce the xylan-enriched fractions. Monosaccharide analysis of 1 and 4 $\mathrm{M} \mathrm{KOH}$ fractions revealed lower levels of xylose $(-18 \%$ to $-24 \%)$ and arabinose $(-19 \%$ to 23\%) in stressed S-roots and plant roots when compared with those of controls (Fig. 2a). The decrease in xylose in the xylan fractions was highly correlated with the decrease in arabinose 
(Pearson's correlation, $\mathrm{r}=0.984, P<0.0001$ ). The ratios of xylosyl to arabinosyl substitutions in grass xylans can vary from 2:1 to 30:1, depending on the tissue and developmental stage of the specific grass evaluated (Hatfield et al., 2017). Our analysis revealed that xylans of maize roots have a high degree of arabinosyl substitutions, with xylose/arabinose ratio between 1.6/1 to 1.9/1. Nevertheless, no differences were observed between the xylose/arabinose ratios of xylans extracted from salt-stressed and control roots.

We next examined whether salt stress led to a reduced abundance of AX or the chain length of AX molecules using size-exclusion chromatography coupled to a multi-angle light scattering detector (SEC-MALS) of $1 \mathrm{M}$ and $4 \mathrm{M} \mathrm{KOH}$ xylan-enriched fractions (Fig. 2b). The average chain lengths of AXs were not different between control and salt-stressed S-roots and plant roots. Although it was difficult to establish the difference in AX abundance between S-roots control and salt-treated samples in $1 \mathrm{M} \mathrm{KOH}$ fractions due to the high baseline, the peaks at 16 min in $1 \mathrm{M} \mathrm{KOH}$ fractions and at $16 \mathrm{~min}$ and $41 \mathrm{~min}$ in $4 \mathrm{M} \mathrm{KOH}$ fractions indicated that the abundances of AXs from stressed roots were lower compared to the respective controls.

Further analysis of the anomeric regions of the two-dimensional heteronuclear single quantum coherence NMR (2D-HSQC-NMR) spectra of S-roots and plant roots confirmed the decrease in AX content in response to salinity (Fig. 3a). The NMR data also confirmed that the relative abundances of xylosyl and arabinosyl residues remained constant in the controls and the stressed roots, suggesting that the AX structure was maintained upon salt stress. We also performed a polysaccharide analysis by carbohydrate gel electrophoresis (PACE) to determine whether changes in AX content had concomitant changes in its decorations. AIRs of S-roots 
and plant roots were separately digested with glycosyl hydrolase (GH) family 10 and 11 endo$\beta 1,4$-xylanases, followed by hydrolysis with GH62 $\alpha$-arabinofuranosidase or GH115 $\alpha$ glucuronidase, and the resulting oligosaccharides were analyzed by PACE (Fig. 3b). Compared to the controls, salt-stressed S-roots and plant roots had no significant differences in the pattern of oligosaccharides released by xylanases. The intensity of each band and the number of fragments were similar for control and NaCl-treated roots. Although PACE analysis revealed no significant changes in quantity and structure of the xylanase digestible fraction of AX, the monosaccharide analysis, SEC-MALS and 2D-NMR results supported an overall reduction in AX quantity.

\section{3 | Salinity modulates cell wall-esterified FA and $p C A$}

The total content of cell wall ester-linked FA and $p$ CA was determined by saponification with $2 \mathrm{M} \mathrm{NaOH}$ followed by RP-HPLC analysis to evaluate the effects of salt stress on cell wall feruloylation and $p$-coumaroylation. Our data show that salt exposure reduced the esterified FA levels by $~ 30 \%$ in S-roots and plant roots, compared to the controls (Fig. 4a). By contrast, the stems of salt-stressed plants had $\sim 80 \%$ more esterified FA in comparison to the control, whereas no significant differences were observed in leaves. Ester-linked pCA decreased in stressed Sroots $(-31 \%)$ and stems (-25\%), while esterified pCA was not significantly affected in plant roots and leaves (Fig. 4b).

In grass cell walls, FA and pCA (at lower levels) are esterified at the xylan $O-5$ position of $\alpha$ $(1,2)$ or $\alpha$-(1,3)-Araf residues (Hatfield et al., 2017). To gain further insight into the nature of the modulation of Araf-bound FA and Araf-bound $p$ CA levels in response to salt stress, the AIR 
was subjected to mild acid hydrolysis in $50 \mathrm{mM}$ TFA to leave the Araf residues esterified to FA or $p$ CA (the FA-Araf or $p$ CA-Araf) followed by saponification and analysis. The content of FA esterified to AX followed the same modulation pattern as found for total ester-linked FA: salt exposure decreased the FA levels in S-roots and plant roots by 38\% and 50\%, respectively (Fig. 4c), albeit an 82\% increase was observed in stems, and no significant difference was observed in leaves. In contrast, salt exposure reduced the $p$ CA content esterified to AX only in S-roots (-34\%) (Fig. 4d). Accordingly, the reductions in FA esterified to AX were strongly correlated with the reduction in xylose (Pearson's correlation, $r=0.922, P<0.0011)$ and arabinose $(r=$ 0.962, $P<0.0001$ ) from xylan fractions (Fig. 2a). There was, however, no significant correlation between $p C A$ esterified to AX with xylose $(r=0.575, P=0.136)$ or arabinose $(r=$ 0.443, $P=0.271$ ). We also examined the ratios between arabinose/FA-Araf in response to salinity. In S-roots, arabinose/FA-Araf ratio increased from 17.6/1 (control samples) to 22.1/1 (salt-stressed samples), with similar increase in plant roots, from 13.9/1 to 22.4/1. Differently, stems reduced the ratio from $18.7 / 1$ to $10.2 / 1$, while leaves exhibited no significant difference $(9.4 / 1$ to $9.6 / 1)$.

The analysis of alkali-released FA and pCA from the remaining TFA-insoluble residue showed that $\sim 80 \%$ of the ester-linked FA of maize cell walls was associated with AX, albeit $\sim 20 \%$ of FA remained in the lignin fraction. The reverse was observed for $p C A$, with $77-94 \%$ of the pCA remaining in the pellet, mostly linked to lignin, whereas only 6-23\% of $p$ CA was esterified to AX fraction. Furthermore, the amounts of FA in the lignin fractions were not altered in response to salt stress (Fig. 4e), whereas the amounts of pCA in the pellets were reduced by $\sim 30 \%$ in S-roots and plant stems (Fig. 4f). Taken together, the reduction in FA content in S- 
roots and plant roots and the increase in stems occurred in the AX fraction but not in the lignin fraction, suggests that salinity modulates the incorporation of FA to the Araf residues of AX.

\section{4 | Salt stress induces the biosynthesis and accumulation of ferulic acid}

In order to elucidate the molecular basis of the modulation in cell wall ester-linked FA content, we further investigated the changes in the expression of genes and the activity of enzymes required to FA biosynthesis in seedlings and plants exposed to salinity. Genes encoding hydroxycinnamaldehyde dehydrogenase (RF2C and RF2D), caffeoyl-CoA 3-Omethyltransferase (CCOAOMT1 and CCoAOMT2) and caffeic acid 3-O-methyltransferase (COMT1) were differentially expressed in response to salt stress (Fig. 5a-e). Although S-roots had no significant differences in $R F 2 C$ and $R F 2 D$ transcript levels in response to salt stress, the plant roots of salt-stressed plants showed higher RF2C (64\%) and RF2D (126\%) transcript levels compared to control plants (Fig. 5a,b). Stems and leaves displayed a similar transcript levels of RF2C and RF2D in control and stressed plants. The transcript abundance of COMT1 was higher in stressed S-roots (47\%) and roots (70\%), and lower in stems (-62\%) and leaves (-85\%) (Fig. 5c). Whereas CCoAOMT1 and CCoAOMT2 expression were $~ 30 \%$ lower in stressed S-roots, their levels were $\sim 45 \%$ higher in plant roots (Fig. 5d,e). Overall, our qPCRbased data suggest that FA biosynthesis is upregulated mainly in plant roots in response to salt stress.

Next, we found that the activity of $p$-hydroxycinnamate-CoA ligase (4CL), which catalyzes the ATP-dependent activation of $p$ CA to $p$-coumaroyl-CoA, was changed upon salt stress when using $p C A$ as substrate (Fig. 5f). Relatively higher activity was observed for 4CL compared to 
the other enzymes. Salt stress reduced 4CL activity by $\sim 40 \%$ in S-roots, roots and stems. We also evaluated the 4CL activity using FA as the substrate. 4CL activity for the formation of feruloyl-CoA was 50\% lower in stressed S-roots and 40\% lower in plant roots, while stressed stems presented $\sim 70 \%$ higher activity, compared to controls (Fig. 5g). Accordingly, 4CL activity followed the similar pattern as found for total ester-linked FA and FA esterified to AX. Hydroxycinnamaldehyde dehydrogenase (HCALDH) and COMT activities were higher in response to salt stress in plant roots and stems. In salt-stressed tissues, HCALDH activity increased by $38 \%$ in S-roots, $128 \%$ in plant roots and $45 \%$ in stems, compared to control plants (Fig. 5h). Similarly, COMT activity increased by $60 \%$ and $45 \%$ in salt-stressed plant roots and stems, respectively (Fig. 5i), with no significant differences in S-roots. Leaves had similar levels of 4CL, HCALDH and COMT activities in control and stressed plants.

Feruloyl esterase (FAE) hydrolyzes the ester-linkage between FA and the Araf residue of AX (Oliveira et al., 2019). Salt stress strongly increased the FAE activity by 300\% in S-roots and plant roots, while it decreased by $40 \%$ in stems (Fig. 5j). The inverse relation between 4CL (using FA as substrate) and FAE activities observed in S-roots, plant roots and stems, suggests a regulatory mechanism between cell wall feruloylation and deferuloylation processes. The upregulation of genes and enzymes involved in FA biosynthesis increased the cytosolic FA levels by $\sim 150 \%$ in salt-stressed S-roots and stems, and by $430 \%$ in plant roots (Fig. 5k,l).

\subsection{Phenolic profile changes following salt exposure}

Because FA biosynthesis was markedly induced by salt treatment in S-roots and plant roots, we investigated possible shifts in the phenolic profiles in response to salinity via reverse-phase 
UHPLC-ESI-Q-ToF-MS of methanol extracts. The differential compounds in each data set are displayed in Table 1 and $\mathbf{2}$. A total of 16,159 peaks (mass-to-charge ratio [ $\mathrm{m} / \mathrm{z}$ ] features) were integrated and aligned across all chromatograms. The PCA analysis of metabolites measured by untargeted metabolomic profiling showed significant differences between control and salttreated samples (Fig. 6a). PC1 (explaining 29\% of the variance) discriminated the phenolic profiles of S-roots and plant roots, while PC2 (explaining 19\% of the variance) provided separation of the profiles of S-roots control from the other profiles (S-roots $\mathrm{NaCl}$, plant roots control and $\mathrm{NaCl})$.

Data sets of S-roots and plant roots presented 175 and 86 differentially abundant compounds caused by salt stress, respectively. From those, 19 were found in common between both data sets. In the data set of S-roots, 60 compounds increased and 115 decreased in the salt-stressed samples when compared with control samples. In plant roots, 20 compounds increased, and 66 compounds decreased in salt-stressed tissues. Comparative analysis of the 19 differential compounds in common between both data sets, five were increased in response to salinity including 4-O-feruloyl quinic acid (7-fold in S-roots and 4-fold in plant roots) and 3-O-feruloyl quinic acid (4-fold in S-roots and 7-fold in plant roots) (Fig. 6b). Ten common differential compounds decreased due to salt stress in both data sets and four decreased in the S-roots but increased in the roots data set due to salt stress. Among them, sinapoyl hexose ( 0.5-fold in Sroots and 4-fold in roots), DIMBOA glucoside (0.4-fold in S-roots and 4-fold in roots) and feruloyl hexose (0.3-fold in S-roots and 7-fold in roots). Furthermore, feruloyl quinic acid isomers were consistently higher under salt stress, whereas the hexosylated phenylpropanoids were lower in the data set of S-roots but restored to normal levels or were even up in the data 
set of plant roots. Therefore, our new findings revealed that salt stress stimulated the accumulation of FA and its derivatives, 3- and 4-O-feruloyl quinic acid.

\section{6 | Salt stress increases lignin content and incorporation of S-units}

To investigate the impact of salt stress on lignification, we determined the lignin content and its monomeric composition. Determination of lignin content using the acetyl bromide method revealed that stressed S-roots, plant roots and stems had 32\%, 15\% and 8\% more lignin than the controls, respectively (Fig. 1d). No change in lignin content was observed in plant leaves after $\mathrm{NaCl}$ treatment.

We next examined the lignin composition using nitrobenzene oxidation. Compared to controls, the total monomeric yields $(\mathrm{G}+\mathrm{S})$ was higher in stressed S-roots, roots and stems, organs that also had increases in lignin amount (Table 3). Salt stress increased the amount of S-unit in all the organs (from $21 \%$ to $147 \%$ ), and to a lesser extent, the amount of G-lignin (from $7 \%$ to $72 \%)$. The mol \% of S-unit increased by $37 \%$ in S-roots and by $27 \%$ in plant roots, whereas the mol \% of G-unit slightly decreased by $\sim 12 \%$ in S-roots and plants roots, indicating that salt stress increased the incorporation of S-units. The increase in S-lignin upon salt stress caused an increase in the S/G ratios, which were $~ 50 \%$ higher in S-roots and plant roots, when compared with the respective controls.

To further explore the lignin compositional shifts, whole-cell walls were analyzed by 2DHSQC-NMR at the gel-state (Kim et al., 2008; Rencoret et al., 2009). The aromatic/unsaturated regions $\left(\delta_{\mathrm{C}} / \delta_{\mathrm{H}} 90-150 / 5.90-7.90\right)$ of the 2D-HSQC-NMR spectra, together with the main 
substructures identified, are shown in Fig. 7. The cross-signals assigned in the HSQC spectra are listed in Table S3. The intensities of the lignin signals, and particularly those of the S-units, increased in cell walls submitted to salt stress of S-roots and plant roots, consistent with the total monomeric yields observed by nitrobenzene oxidation and the higher lignin content. The magnitude of the increase in S-units estimated from the normalized integrals (24-37\%) was quite similar to that estimated biochemically (27-37\%) for roots of seedlings and plants. In general, the NMR data largely corroborated the data obtained by nitrobenzene oxidation analysis, indicating a higher deposition of S-units in lignin of S-roots and plant roots in response to salt stress and, consequently, an overall increase in the S/G ratios. In accordance with the biochemical determination, the total FA identified by 2D-NMR was reduced by $48 \%$ in S-roots and by 39\% in plant roots, and increased by $75 \%$ in stems, in response to salt stress. The crosssignals corresponding to $\mathrm{H}$-lignin units overlapped with intense signals of phenylalanine residues from proteins. Therefore, the relative abundance of $\mathrm{H}$-units could not be determined. Signals for tricin, a flavone that is incorporated into the lignin of grasses (del Río et al., 2012; Lan et al., 2015), were observed in the HSQC spectra of the aerial parts of the plants (stems and leaves) but were absent in roots of seedlings and plants. Nevertheless, no major differences were observed in the relative abundances of tricin in stems and leaves of plants grown under salt stress, compared to the controls.

\section{4 | DISCUSSION}


Plant cell wall composition and metabolism are dynamically regulated in response to a variety of environmental stresses. Our data represents the first detailed study of changes in cell wall polysaccharides, feruloylation, lignification and phenolic metabolism upon exposure to salinity in a grass species. Salt stress modulated the deposition of cellulose, matrix polysaccharides and lignin in tissues of roots and stems of maize (see Table 4 for the summary of the main alterations in response to salinity). We show reductions of AX content and its feruloylation triggered by salinity, followed by increases in lignin amounts and the incorporation of S-units in S-roots and plant roots. The expression of genes and enzyme activities enrolled in phenylpropanoid biosynthesis were modified by salinity in a consistent manner with the structural changes observed in each studied organ. Fig. 8 shows a model of grass cell wall biosynthesis integrating the extensive cell wall remodeling in response to salinity.

Our data indicate that different tissues respond differently to salinity. Although maize leaves had significant reductions of growth parameters (Fig. S4), they presented subtle alterations in cell wall composition triggered by salt stress (Table 4). The effects were restricted to a slight increase in the content of matrix polysaccharides, arabinose, glucose, and the frequency of Sunits in lignin assessed by 2D-NMR. In turn, S-roots, plant roots and, to a lesser extent the stems, exhibited more significant changes in their cell walls. In addition to increased lignin content, stressed S-roots and plant roots showed a significant reduction in the content of xylose, arabinose, galactose and FA. Given that roots are the first organ confronted with salinity, the effects of exposure to high concentrations of salt and the ions $\mathrm{Na}^{+}$and $\mathrm{Cl}^{-}$are expected to be more evident in roots than in aerial parts of the plant (Farooq et al., 2015; Dinneny, 2019). 
Despite the recent progress in our understanding of cell wall feruloylation (Bartley et al., 2013; Buanafina et al., 2016; de Souza et al., 2018; de Souza et al., 2019), the modulation of this process in response to abiotic stress is still not well understood. In wheat coleoptiles, osmotic stress suppresses cell wall stiffening and reduces the total FA content (Wakabayashi et al., 1997). Later work demonstrated that an increase in FA content in maize cell walls in response to salt stress is associated with the suppression of shoot growth (Uddin et al., 2014). Similarly, our results showed that exposure to salinity suppressed the growth of maize stems followed by increased levels of FA. By contrast, salt stress caused the suppression of the growth of S-roots and plant roots and reduction in the feruloylation of AX. These results suggest that different tissues respond differently to salinity and the suppression of root growth in seedlings and plants is, at least in part, due to the lower abundance of AX (Fig. 2, 4). In addition to decreased xylose residues, stressed S-roots and roots had a significant reduction in arabinose residues in the $1 \mathrm{M}$ and $4 \mathrm{M} \mathrm{KOH}$ cell wall fractions, reflecting an overall decrease in AX abundance. Our data indicate that reductions in xylosyl residues lead, consequently, to a reduction in arabinosyl residues carrying feruloyl esters. The reduced level of cell wall-bound FA in the salt-stressed roots reduces the cross-links between AXs and lignin. Rice mutants lacking the xylosyltransferase activity from glycosyltransferase family GT61, $X A X 1$, had reduced FA and xylosyl residues of xylan (Chiniquy et al., 2012). Similarly, suppression of the Brachypodium glycosyltransferase family 43 BdGT43A, which is implicated in the xylan backbone elongation, leads to a decrease in AX abundance associated with lower levels of FA (Whitehead et al., 2018). 
Besides the reduced AX abundance in salt-stressed S-roots and plant roots, the increases in arabinose/FA-Araf ratios in these organs demonstrate that FA-Araf amounts reduced to a greater extent. A possible explanation for this phenomenon is the decrease of 4CL activity in S-roots and plant roots. This enzyme converts FA to feruloyl-CoA, an essential step for feruloylation of AX. In addition, stems presented significantly higher FA-Araf content ( 80\%) and 4CL activity ( 70\%) in response to salinity. Feruloylation of AXs and lignins are both known to be catalyzed by BAHD acyl-CoA transferases, using feruloyl-CoA as acyl-donor. Specific BAHD acyl-CoA transferases are involved in the feruloylation of AXs in grasses, $B$. distachyon (Buanafina et al., 2016), Setaria viridis (de Souza et al., 2018) and sugarcane (de Souza et al., 2019). Although further studies are required to demonstrate that the BAHD genes are responsive to salinity, our results suggest a regulatory mechanism between cell wall feruloylation and deferuloylation. In addition, the increase in FAE activity in response to salinity in S-roots and plant roots can also lead to a higher FA removal from Araf residues, contributing to the deferuloylation of AX (Fig. 8). Therefore, maize FAE is likely to be implicated in controlling the degree of AX feruloylation during abiotic stress.

We observed higher lignin content in secondary cell walls in response to salt stress. Lignin is involved in plant responses to abiotic stress and lignin biosynthetic genes are induced during plant acclimation to salt stress (Moura et al., 2010; Neves et al., 2010). The overexpression of MYB46 and NAC012 transcription factors responsible for the coordinated expression of secondary cell wall biosynthetic genes led to enhanced tolerance to salt and osmotic stress, by upregulating the expression of genes encoding lignin biosynthetic enzymes, resulting in higher lignin deposition in secondary cell walls (Guo et al., 2017; Hu et al., 2019). Salt stress also 
promoted reductions in cellulose and/or matrix polysaccharides, concomitantly with increases in lignin content (Fig. 1d). The regulation of cellulose and lignin deposition in response to salinity may represent an adaptation to provide mechanical support to cell walls, suggesting crosstalk during cell wall biosynthesis (Hu et al., 1999; Burton et al., 2010; Byrt et al., 2018). This crosstalk is consistent with the fact that during cell wall formation plants regulate the deposition of lignin and cellulose (Hu et al., 1999; Burton et al., 2010; Byrt et al., 2018), and matrix polysaccharides (Van Acker et al., 2013).

2D-HSQC-NMR spectroscopy of whole-cell walls and lignin compositional analysis with alkaline nitrobenzene oxidation followed by liquid chromatography revealed that salt stress increases lignin content and promotes higher incorporation of predominantly S-units, with the consequent increase in the $S / G$ ratio (Table 3). This finding suggests that maize cells can redirect the carbon flux upon salinity from the biosynthesis of cell wall polysaccharides to lignin, such redirection of the flux has a particularly strong effect toward S-units, resulting in plants with increased S-units in lignin polymer (Hu et al., 1999; Verbancic et al., 2018). Lignin enriched in S-units is composed primarily of ether-type $\beta-O-4$ bonds, due to the presence of a methoxyl group at the C5 position of the syringyl moiety that prevents the formation of covalent bonds at this position (Ralph et al., 2004). The methoxyl group at the C5 position diminishes the complexity of the lignin polymer, as compared to the G-rich lignins that are richer in condensed $\beta-5$ and 5-5/4-O- $\beta$ bonds (Mottiar et al., 2016; Ralph et al., 2019). More importantly, the higher lignin content in secondary cell walls acts as diffusion barrier to limit salt, $\mathrm{Na}^{+}$and $\mathrm{Cl}^{-}$entry into xylem vessels and ultimately into the shoots (Byrt et al., 2018). This 
suggests that lignin deposition during salt stress is a dynamic process for the reinforcement of cell walls (Vaahtera et al., 2019).

The decreased content of $p C A$ ester-linked to lignin in stressed tissues is interesting and somewhat unexpected. Maize lignins contain relatively large amounts of pCA acylating preferentially S-units, but also G-units (Grabber et al., 1996; Hatfield et al., 2009). Although it was envisioned that S-enriched lignins in salt-stressed tissues would present higher levels of pCA, we observed the contrary (Fig. 4f). It is known that $\gamma$-p-coumaroylation of monolignols occurs through acylation of canonical monolignols using $p$-coumaroyl-CoA as the acyl-donor, and catalyzed by p-coumaroyl-CoA:monolignol transferase (PMT) (Withers et al., 2012; Petrik et al., 2014). Considering that grasses produce $\gamma$-p-coumaroylated S-lignins when concentrations of sinapyl alcohol and p-coumaroyl-CoA as substrates are sufficient and available for PMT activity (Takeda et al., 2018), the reduced 4CL activity in response to salinity may have resulted in lower concentrations of p-coumaroyl-CoA available to PMT, in turn resulting in a diminished cellular pool of substrate for the $\gamma$-p-coumaroylation of lignins (Fig. 8).

Given that salt stress reduces the abundance of feruloylated AX, and concomitantly increases S-lignin content, we infer that cell walls of salt-stressed tissues present fewer covalent linkages between polysaccharides and lignin components. A recent study demonstrated that hydroxyl groups in xylan of secondary cell walls have abundant electrostatic interactions with methoxyl groups found mainly on S-units of the lignin polymer (Kang et al., 2019). In turn, xylan substitutions with arabinose residues determine the strength of the covalent interactions of wall 
polysaccharides (i.e. binding of xylan to cellulose), modifying the mechanical properties of the wall (Simmons et al., 2016; Grantham et al., 2017; Hatfield et al., 2017).

Genetic and biochemical studies suggest that FA can be biosynthesized via two different metabolic pathways (de Oliveira et al., 2015). In maize, two cytosolic aldehyde dehydrogenases, REF2C and REF2D, catalyze the oxidation of coniferaldehyde to FA (Nair et al., 2004; Končitíková et al., 2015; Ferro et al., 2020). Alternatively, FA might also be produced from caffeic acid via 3-O-methylation by COMT (Fornalé et al., 2017). Our RT-qPCR-based analysis and enzyme assays revealed differential expression patterns for FA biosynthesis (Fig. 5). We observed an increase in cytosolic FA by $150 \%$ to $430 \%$ in S-roots, roots and stems in response to salinity, which can be attributed, at least in part, to the redirection of carbon flux from the biosynthesis of G-unit to the biosynthesis of cytosolic FA, by the oxidation of coniferaldehyde to FA by HCALDH (Fig. 8). Our findings revealed that salt stress increases cytosolic FA levels by increasing its de novo biosynthesis, and by removing the ester-linked FA from AX. De novo biosynthesis of FA also increases in stems, but in contrast, it is followed by FA activation to feruloyl-CoA and subsequent esterification to AX accompanied by reduced FAE activity.

The phenolic profiling of S-roots and plant roots allowed to evaluate how the carbon flux through the phenylpropanoid pathway was redirected in response to salt stress. We found that most of the compounds with increased abundance in S-roots and plant roots were the FA derivates 3- and 4-O-feruloyl quinic acids, consistent with the increased flux towards FA formation (Fig. 8). The increase in cytosolic FA is likely associated with the increase in the 
osmotic pressure promoted by the external $\mathrm{NaCl}$, and to play antioxidant protection against the toxicity of the absorbed $\mathrm{NaCl}$ (de Oliveira et al., 2015).

In conclusion, our results reveal that the broad compositional alterations in maize cell walls in response to salinity are largely attributed to the reductions in cellulose and/or matrix polysaccharide amounts, the reduced feruloylation of arabinosyl moieties linked to AXs, and higher incorporation of S-units in lignin polymer. Moreover, this study provides new insights into salt-induced modulations in the expression of genes and enzyme activities required for FA biosynthesis and cell wall feruloylation, such as 4CL, HCALDH and FAE. Genetic modification of these candidate targets may contribute to develop resilient crops to increased salinity. This study provides a better understanding of how plants cope with a saline environment by modulating the composition and structure of their cell walls and the phenolic metabolism.

\section{ACKNOWLEDGMENTS}

This work was supported by the Brazilian National Council for Scientific and Technological Development (CNPq) and the Coordination of Enhancement of Higher Education Personnel (CAPES). D.M.O. and T.RM. gratefully acknowledge the doctoral scholarships granted by CNPq (GM/GD - 141076/2016-0) and the doctoral scholarships abroad granted by CAPES (PDSE - 88881.188627/2018-01 and 88881.188639/2018-01). D.K. and R.K. were supported by the Czech Science Foundation (grant No. 18-07563S) and the Ministry of Education, Youth 
and Sports of the Czech Republic (CZ.02.1.01/0.0/0.0/16_019/0000827). J.C.d.R., J.R., and A.G. were funded by the Spanish project AGL2017-83036-R (financed by Ministerio de Economía y Competitividad, Agencia Estatal de Investigación, AEI, and Fondo Europeo de Desarrollo Regional, FEDER). We are also grateful to the University of York Bioscience Technology Facility for performing the SEC-MALS analysis.

\section{AUTHOR CONTRIBUTIONS}

D.M.O. and W.D.S. designed the research. D.M.O., T.R.M., F.V.S., R.C.S., R.K., D.K., R.S., M.S., G.G., K.M., J.R., A.G. and T.T. performed the experiments. D.M.O., K.M., J.R., R.M., P.D., J.C.d.R., W.B., S.M.M., L.D.G., O.F.F. and W.D.S. assisted the experimental design, analyzed and discussed the data. D.M.O. wrote the manuscript with contributions from all the coauthors. All authors approved the final version of the manuscript.

\section{CONFLICT OF INTEREST}

The authors declare no conflict of interest. 


\section{REFERENCES}

Anders, N., Wilkinson, M.D., Lovegrove, A., Freeman, J., Tryfona, T., Pellny, T.K., Weimar, T., Mortimer, J.C., Stott, K., Baker, J.M., Defoin-Platel, M., Shewry, P.R., Dupree, P. \& Mitchell. R.A. (2012) Glycosyl transferases in family 61 mediate arabinofuranosyl transfer onto xylan in grasses. Proceedings of the National Academy of Sciences of the United States of America, 109, 989-993.

Bartley, L.E., Peck, M.L., Kim, S.R., Ebert, B., Manisseri, C., Chiniquy, D.M., Sykes, R., Gao, L., Rautengarten, C., Vega-Sanchez, M.E., Benke, P.I., Canlas, P.E., Cao, P., Brewer, S., Lin, F., Smith, W.L., Zhang, X., Keasling, J.D., Jentoff, R.E., Foster, S.B., Zhou, J., Ziebell, A., An, G., Scheller, H.V. \& Ronald, P.C. (2013) Overexpression of a BAHD acyltransferase, OsAt10, alters rice cell wall hydroxycinnamic acid content and saccharification. Plant Physiology, 161, 1615-1633.

Bevilaqua, J.M., Finger-Teixeira, A., Marchiosi, R., Oliveira, D.M., Joia, B.M., Ferro, A.P., Parizotto, A.V., dos Santos, W.D. \& Ferrarese-Filho, O. (2019) Exogenous application of rosmarinic acid improves saccharification without affecting growth and lignification of maize. Plant Physiology and Biochemistry, 142, 275-282.

Brown, D.M., Zhang, Z., Stephens, E., Dupree, P. \& Turner, S.R. (2009) Characterization of IRX10 and IRX10-like reveals an essential role in glucuronoxylan biosynthesis in Arabidopsis. Plant Journal, 57(4), 732-746.

Buanafina, M.M., Fescemyer, H.W., Sharma, M. \& Shearer, E.A. (2016) Functional testing of a PF02458 homologue of putative rice arabinoxylan feruloyl transferase genes in Brachypodium distachyon. Planta, 243, 659-674.

Burton, R.A., Gidley, M.J. \& Fincher, G.B. (2010) Heterogeneity in the chemistry, structure and function of plant cell walls. Nature Chemical Biology, 6, 724-732.

Busse-Wicher, M., Li, A., Silveira, R.L., Pereira, C.S., Tryfona, T., Gomes, T.C., Skaf, M.S. \& Dupree, P. (2016) Evolution of xylan substitution patterns in gymnosperms and angiosperms: implications for xylan interaction with cellulose. Plant Physiology, 171, 2418-2431.

Byrt, C.S., Munns, R., Burton, R.A., Gilliham, M. \& Wege, S. (2018) Root cell wall solutions for crop plants in saline soils. Plant Science, 269, 47-55.

Cesarino, I. (2019) Structural features and regulation of lignin deposited upon biotic and abiotic stresses. Current Opinion in Biotechnology, 56, 209-214.

Chiniquy, D., Sharma, V., Schultink, A., Baidoo, E.E., Rautengarten, C., Cheng, K., Carroll, A., Ulvskov, P., Harholt, J., Keasling, J.D., Pauly, M., Scheller, H.V. \& Ronald, P.C. (2012) XAX1 from glycosyltransferase family 61 mediates xylosyltransfer to rice xylan. Proceedings of the National Academy of Sciences of the United States of America, 109, 17117-17122. 
de Oliveira, D.M., Finger-Teixeira, A., Mota, T.R., Salvador, V.H., Moreira-Vilar, F.C., Molinari, H.B., Mitchell, R.A., Marchiosi, R., Ferrarese-Filho, O. \& dos Santos, W.D. (2015) Ferulic acid: a key component in grass lignocellulose recalcitrance to hydrolysis. Plant Biotechnology Journal, 13, 1224-1232.

de Souza, W.R., Martins, P.K., Freeman, J., Pellny, T.K., Michaelson, L.V., Sampaio, B.L., Vinecky, F., Ribeiro, A.P., da Cunha, B., Kobayashi, A.K., de Oliveira, P.A., Campanha, R.B., Pacheco, T.F., Martarello, D.C.I., Marchiosi, R., Ferrarese-Filho, O., dos Santos, W.D., Tramontina, R., Squina, F.M., Centeno, D.C., Gaspar, M., Braga, M.R., Tine, M.A.S., Ralph, J., Mitchell, R.A.C. \& Molinari, H.B.C. (2018) Suppression of a single BAHD gene in Setaria viridis causes large, stable decreases in cell wall feruloylation and increases biomass digestibility. New Phytologist, 218, 81-93.

de Souza, W.R., Pacheco, T.F., Duarte, K.E., Sampaio, B.L., de Oliveira Molinari, P.A., Martins, P.K., Santiago, T.R., Formighieri, E.F., Vinecky, F., Ribeiro, A.P., da Cunha, B.A.D.B., Kobayashi, A.K., Mitchell, R.A.C., Gambetta D.S.R. \& Molinari, H.B.C. (2019) Silencing of a BAHD acyltransferase in sugarcane increases biomass digestibility. Biotechnology for Biofuels, 12, 111.

del Río, J.C., Rencoret, J., Prinsen, P., Martínez, Á.T., Ralph, J. \& Gutiérrez, A. (2012) Structural characterization of wheat straw lignin as revealed by analytical pyrolysis, 2D-NMR, and reductive cleavage methods. Journal of Agricultural and Food Chemistry, 60, 5922-5935.

Dinneny, J.R. (2019) Developmental responses to water and salinity in root systems. Annual Review of Cell and Developmental Biology, 35, 239-257.

Dong, J., Wu, F., \& Zhang, G. (2006) Influence of cadmium on antioxidant capacity and four microelement concentrations in tomato seedlings (Lycopersicon esculentum). Chemosphere, 64, 1659-1666

Endler, A., Kesten, C., Schneider, R., Zhang, Y., Ivakov, A., Froehlich, A., Funke, N. \& Persson, S. (2015) A mechanism for sustained cellulose synthesis during salt stress. Cell, 162, 1353-1364.

Farooq, M., Hussain, M., Wakeel, A. \& Siddique, K.H.M. (2015) Salt stress in maize: effects, resistance mechanisms, and management. A review. Agronomy for Sustainable Development, 35, 461481.

Ferro, A.P., Flores Júnior, R., Finger-Teixeira, A., Parizotto, A.V., Bevilaqua, J.M., Oliveira, D.M., Molinari, H.B.C., Marchiosi, R., dos Santos, W.D., Seixas, F.A.V. \& Ferrarese-Filho, O. (2020). Inhibition of Zea mays coniferyl aldehyde dehydrogenase by daidzin: A potential approach for the investigation of lignocellulose recalcitrance. Process Biochemistry, 90, 131-138.

Fornalé, S., Rencoret, J., García-Calvo, L., Encina, A., Rigau, J., Gutiérrez, A., del Río, J.C. \& CaparrósRuiz, D. (2017) Changes in cell wall polymers and degradability in maize mutants lacking 3'and 5'-O-methyltransferases involved in lignin biosynthesis. Plant and Cell Physiology, 58(2), 240-255. 
Foster, C.E., Martin, T.M. \& Pauly, M. (2010). Comprehensive compositional analysis of plant cell walls (lignocellulosic biomass) part II: carbohydrates. Journal of Visualized Experiments (37), 1837.

Gladala-Kostarz, A., Doonan, J. H., \& Bosch, M. (2020). Mechanical stimulation in Brachypodium distachyon: Implications for fitness, productivity, and cell wall properties. Plant, Cell \& Environment. DOI:10.1111/pce.13724

Goubet, F., Barton, C.J., Mortimer, J.C., Yu, X., Zhang, Z., Miles, G.P., Richens, J., Liepman, A.H., Seffen, K. \& Dupree, P. (2009) Cell wall glucomannan in Arabidopsis is synthesised by CSLA glycosyltransferases, and influences the progression of embryogenesis. Plant Journal, 60(3), 527-538.

Goubet, F., Jackson, P., Deery, M.J. \& Dupree, P. (2002) Polysaccharide analysis using carbohydrate gel electrophoresis: a method to study plant cell wall polysaccharides and polysaccharide hydrolases. Analytical Biochemistry, 300(1), 53-68.

Grabber, J.H., Quideau, S. \& Ralph, J. (1996) p-Coumaroylated syringyl units in maize lignin: Implications for $\beta$-ether cleavage by thioacidolysis. Phytochemistry, 43, 1189-1194.

Grabber, J.H., Ralph, J. \& Hatfield, R.D. (2000) Cross-linking of maize walls by ferulate dimerization and incorporation into lignin. Journal of Agricultural and Food Chemistry, 48, 6106-6113.

Grantham, N.J., Wurman-Rodrich, J., Terrett, O.M., Lyczakowski, J.J., Stott, K., Iuga, D., Simmons, T.J., Durand-Tardif, M., Brown, S.P., Dupree, R., Busse-Wicher \& M., Dupree, P. (2017) An even pattern of xylan substitution is critical for interaction with cellulose in plant cell walls. Nature Plants, 3, 859-865.

Guo, H., Wang, Y., Wang, L., Hu, P., Wang, Y., Jia, Y., Zhang, C., Zhang, Y., Zhang, Y., Wang, C. \& Yang, C. (2017) Expression of the MYB transcription factor gene BplMYB46 affects abiotic stress tolerance and secondary cell wall deposition in Betula platyphylla. Plant Biotechnology Journal, 15, 107-121.

Hatfield, R.D., Marita, J.M., Frost, K., Grabber, J., Ralph, J., Lu, F. \& Kim, H. (2009) Grass lignin acylation: p-coumaroyl transferase activity and cell wall characteristics of C3 and C4 grasses. Planta, 229, 1253-1267.

Hatfield, R.D., Rancour, D.M. \& Marita, J.M. (2017) Grass cell walls: a story of cross-linking. Frontiers in Plant Science, 7, 2056.

Hu, P., Zhang, K. \& Yang, C. (2019) BpNAC012 positively regulates abiotic stress responses and secondary wall biosynthesis. Plant Physiology, 179, 700-717.

Hu, W.-J., Harding, S.A., Lung, J., Popko, J.L., Ralph, J., Stokke, D.D., Tsai, C.-J. \& Chiang, V.L. (1999) Repression of lignin biosynthesis promotes cellulose accumulation and growth in transgenic trees. Nature Biotechnology, 17, 808-812. 
Jones, L., Milne, J.L., Ashford, D. \& McQueen-Mason, S.J. (2003) Cell wall arabinan is essential for guard cell function. Proceedings of the National Academy of Sciences of the United States of America, 100, 11783-11788.

Kang, X., Kirui, A., Widanage, M.C.D., Mentink-Vigier, F., Cosgrove, D.J. \& Wang, T. (2019) Ligninpolysaccharide interactions in plant secondary cell walls revealed by solid-state NMR. Nature Communications, 10, 347.

Karlen, S.D., Free, H.C., Padmakshan, D., Smith, B.G., Ralph, J. \& Harris, P.J. (2018) Commelinid monocotyledon lignins are acylated by p-coumarate. Plant Physiology, 177, 513-521.

Karlen, S.D., Zhang, C., Peck, M.L., Smith, R.A., Padmakshan, D., Helmich, K.E., Free, H.C.A., Lee, S., Smith, B.G., Lu, F., Sedbrook, J.C., Sibout, R., Grabber, J.H., Runge, T.M., Mysore, K.S., Harris, P.J., Bartley, L.E. \& Ralph, J. (2016) Monolignol ferulate conjugates are naturally incorporated into plant lignins. Science Advances, 2, e1600393.

Kesten, C., Wallmann, A., Schneider, R., McFarlane, H.E., Diehl, A., Khan, G.A., van Rossum, B.J., Lampugnani, E.R., Szymanski, W.G., Cremer, N., Schmieder, P., Ford, K.L., Seiter, F., Heazlewood, J.L., Sanchez-Rodriguez, C., Oschkinat, H. \& Persson, S. (2019) The companion of cellulose synthase 1 confers salt tolerance through a Tau-like mechanism in plants. Nature Communications, 10, 857.

Kim, H., Padmakshan, D., Li, Y., Rencoret, J., Hatfield, R.D. \& Ralph, J. (2017) Characterization and elimination of undesirable protein residues in plant cell wall materials for enhancing lignin analysis by solution-state Nuclear Magnetic Resonance spectroscopy. Biomacromolecules, 18(12), 4184-4195.

Kim, H., Ralph, J. \& Akiyama, T. (2008) Solution-state 2D NMR of ball-milled plant cell wall gels in DMSO-d $\mathrm{d}_{6}$. Bioenergy Research, 1, 56-66.

Končitíková, R., Vigouroux, A., Kopečná, M., Andree, T., Bartos, J., Sebela, M., Morera, S. \& Kopecny, D. (2015) Role and structural characterization of plant aldehyde dehydrogenases from family 2 and family 7. Biochemical Journal, 468, 109-123.

Lan, W., Lu, F., Regner, M., Zhu, Y., Rencoret, J., Ralph, S.A., Zakai, U.I., Morreel, K., Boerjan, W. \& Ralph, J. (2015) Tricin, a flavonoid monomer in monocot lignification. Plant Physiology, 167, 1284-1295.

Le Gall, H., Philippe, F., Domon, J.M., Gillet, F., Pelloux, J. \& Rayon, C. (2015) Cell wall metabolism in response to abiotic sstress. Plants (Basel), 4, 112-166.

Marriott, P.E., Sibout, R., Lapierre, C., Fangel, J.U., Willats, W.G., Hofte, H., Gomez, L.D. \& McQueen-Mason, S.J. (2014) Range of cell-wall alterations enhance saccharification in Brachypodium distachyon mutants. Proceedings of the National Academy of Sciences of the United States of America, 111, 14601-14606.

Moreira-Vilar, F.C., Siqueira-Soares, R.d.C., Finger-Teixeira, A., de Oliveira, D.M., Ferro, A.P., da Rocha, G.J., Ferrarese, M.L.L., dos Santos, W.D. \& Ferrarese-Filho, O. (2014) The acetyl 
bromide method is faster, simpler and presents best recovery of lignin in different herbaceous tissues than klason and thioglycolic acid methods. PLOS ONE, 9(10), e110000.

Morreel, K., Goeminne, G., Storme, V., Sterck, L., Ralph, J., Coppieters, W., Breyne, P., Steenackers, M., Georges, M., Messens, E. \& Boerjan, W. (2006) Genetical metabolomics of flavonoid biosynthesis in Populus: a case study. Plant Journal, 47, 224-237.

Morreel, K., Saeys, Y., Dima, O., Lu, F., Van de Peer, Y., Vanholme, R., Ralph, J., Vanholme, B. \& Boerjan, W. (2014) Systematic structural characterization of metabolites in Arabidopsis via candidate substrate-product pair networks. Plant Cell, 26, 929-945.

Mota, T.R., Oliveira, D.M., Morais, G.R., Marchiosi, R., Buckeridge, M.S., Ferrarese-Filho, O., \& dos Santos, W.D. (2019). Hydrogen peroxide-acetic acid pretreatment increases the saccharification and enzyme adsorption on lignocellulose. Industrial Crops and Products, 140, 111657.

Mottiar, Y., Vanholme, R., Boerjan, W., Ralph, J. \& Mansfield, S.D. (2016) Designer lignins: harnessing the plasticity of lignification. Current Opinion in Biotechnology, 37, 190-200.

Moura, J.C., Bonine, C.A., de Oliveira Fernandes Viana, J., Dornelas, M.C. \& Mazzafera, P. (2010) Abiotic and biotic stresses and changes in the lignin content and composition in plants. Journal of Integrative Plant Biology, 52, 360-376.

Munns, R., Passioura, J.B., Colmer, T.D. \& Byrt, C.S. (2019) Osmotic adjustment and energy limitations to plant growth in saline soil. New Phytologist, 225(3), 1091-1096.

Munns, R. \& Tester, M. (2008) Mechanisms of salinity tolerance. Annual Review of Plant Biology, 59, 651-681.

Nair, R.B., Bastress, K.L., Ruegger, M.O, Denault, J.W. \& Chapple, C. (2004) The Arabidopsis thaliana REDUCED EPIDERMAL FLUORESCENCE1 gene encodes an aldehyde dehydrogenase involved in ferulic acid and sinapic acid biosynthesis. Plant Cell, 16, 544-554.

Negrão, S., Schmockel, S.M. \& Tester, M. (2017) Evaluating physiological responses of plants to salinity stress. Annals of Botany, 119, 1-11.

Neves, G.Y.S., Marchiosi, R., Ferrarese, M.L.L., Siqueira-Soares , R.C. \& Ferrarese-Filho , O. (2010) Root growth inhibition and lignification induced by salt stress in soybean. Journal of Agronomy and Crop Science, 196, 467-473.

Oliveira, D.M., Mota, T.R., Grandis, A., de Morais, G.R., de Lucas, R.C., Polizeli, M.L.T.M., Marchiosi, R., Buckeridge, M.S., Ferrarese-Filho, O. \& dos Santos, W.D. (2020) Lignin plays a key role in determining biomass recalcitrance in forage grasses. Renewable Energy, 147, 22062217.

Oliveira, D.M., Mota, T.R., Oliva, B., Segato, F., Marchiosi, R., Ferrarese-Filho, O., Faulds, C.B. \& dos Santos, W.D. (2019) Feruloyl esterases: Biocatalysts to overcome biomass recalcitrance and for the production of bioactive compounds. Bioresource Technology, 278, 408-423. 
Petrik, D.L., Karlen, S.D., Cass, C.L., Padmakshan, D., Lu, F., Liu, S., Le Bris, P., Antelme, S., Santoro, N., Wilkerson, C.G., Sibout, R., Lapierre, C., Ralph, J. \& Sedbrook, J.C. (2014) p-CoumaroylCoA:monolignol transferase (PMT) acts specifically in the lignin biosynthetic pathway in Brachypodium distachyon. Plant Journal, 77, 713-726.

Ralph, J. (2010) Hydroxycinnamates in lignification. Phytochemistry Reviews, 9, 65-83.

Ralph, J., Lapierre, C. \& Boerjan, W. (2019) Lignin structure and its engineering. Current Opinion in Biotechnology, 56, 240-249.

Ralph, J., Lundquist, K., Brunow, G., Lu, F., Kim, H., Schatz, P.F., Marita, J.M., Hatfield, R.D., Ralph, S.A., Christensen, J.H. \& Boerjan, W. (2004) Lignins: Natural polymers from oxidative coupling of 4-hydroxyphenyl- propanoids. Phytochemistry Reviews, 3, 29-60.

Rencoret, J., Marques, G., Gutiérrez, A., Nieto, L., Santos, J.I., Jiménez-Barbero, J., Martínez, Á.T. \& del Río, J.C. (2009) HSQC-NMR analysis of lignin in woody (Eucalyptus globulus and Picea abies) and non-woody (Agave sisalana) ball-milled plant materials at the gel state. Holzforschung, 63, 691-698.

Rennie, E.A. \& Scheller, H.V. (2014) Xylan biosynthesis. Current Opinion in Biotechnology, 26, 100107.

Rui, Y. and Dinneny, J.R. (2019) A wall with integrity: surveillance and maintenance of the plant cell wall under stress. New Phytologist, 225 (4), 1428-1439.

Simmons, T.J., Mortimer, J.C., Bernardinelli, O.D., Poppler, A.C., Brown, S.P., de Azevedo, E.R., Dupree, R. \& Dupree, P. (2016) Folding of xylan onto cellulose fibrils in plant cell walls revealed by solid-state NMR. Nature Communications, 7, 13902.

Takeda, Y., Tobimatsu, Y., Karlen, S.D., Koshiba, T., Suzuki, S., Yamamura, M., Murakami, S., Mukai, M., Hattori, T., Osakabe, K., Ralph, J., Sakamoto, M. \& Umezawa, T. (2018) Downregulation of $p$-COUMAROYL ESTER 3-HYDROXYLASE in rice leads to altered cell wall structures and improves biomass saccharification. Plant Journal, 95(5), 796-811.

Tenhaken, R. (2014) Cell wall remodeling under abiotic stress. Frontiers in Plant Science, 5, 771.

Tryfona, T., Sorieul, M., Feijao, C, Stott, K., Rubtsov, D.V., Anders, N. \& Dupree, P. (2019) Development of an oligosaccharide library to characterise the structural variation in glucuronoarabinoxylan in the cell walls of vegetative tissues in grasses. Biotechnology for Biofuels, 12, 109.

Uddin, M.N., Hanstein, S., Faust, F., Eitenmuller, P.T., Pitann, B, \& Schubert, S. (2014) Diferulic acids in the cell wall may contribute to the suppression of shoot growth in the first phase of salt stress in maize. Phytochemistry, 102, 126-136.

Vaahtera, L., Schulz, J. \& Hamann, T. (2019) Cell wall integrity maintenance during plant development and interaction with the environment. Nature Plants, 5, 924-932. 
Van Acker, R., Vanholme, R., Storme, V., Mortimer, J.C., Dupree, P. \& Boerjan, W. (2013) Lignin biosynthesis perturbations affect secondary cell wall composition and saccharification yield in Arabidopsis thaliana. Biotechnology for Biofuels, 6, 46.

Vanholme, R., De Meester, B., Ralph, J. \& Boerjan, W. (2019) Lignin biosynthesis and its integration into metabolism. Current Opinion in Biotechnology, 56, 230-239.

Vanholme, R., Demedts, B., Morreel, K., Ralph, J. \& Boerjan, W. (2010) Lignin biosynthesis and structure. Plant Physiology, 153, 895-905.

Verbancic, J., Lunn, J.E., Stitt, M. \& Persson, S. (2018) Carbon supply and the regulation of cell wall synthesis. Molecular Plant, 11, 75-94.

Voiniciuc, C., Pauly, M. \& Usadel, B. (2018) Monitoring polysaccharide dynamics in the plant cell wall. Plant Physiology, 176, 2590-2600

Wakabayashi, K., Hoson, T. \& Kamisaka, S. (1997) Osmotic stress suppresses cell wall stiffening and the increase in cell wall-bound ferulic and diferulic acids in wheat coleoptiles. Plant Physiology, 113, 967-973.

Wang, T., McFarlane, H.E. \& Persson, S. (2016) The impact of abiotic factors on cellulose synthesis. Journal of Experimental Botany, 67, 543-552.

Whitehead, C., Garrido, F.J.O., Reymond, M., Simister, R., Distelfeld, A., Atienza, S.G., Piston, F., Gomez, L.D. \& McQueen-Mason, S.J. (2018) A glycosyl transferase family 43 protein involved in xylan biosynthesis is associated with straw digestibility in Brachypodium distachyon. New Phytologist, 218, 974-985.

Wilkerson, C.G., Mansfield, S.D., Lu, F., Withers, S., Park, J.Y., Karlen, S.D., Gonzales-Vigil, E., Padmakshan, D., Unda, F., Rencoret, J. \& Ralph, J. (2014) Monolignol ferulate transferase introduces chemically labile linkages into the lignin backbone. Science, 344, 90-93.

Withers, S., Lu, F., Kim, H., Zhu, Y., Ralph, J. \& Wilkerson, C.G. (2012) Identification of grass-specific enzyme that acylates monolignols with p-coumarate. Journal of Biological Chemistry, 287, 8347-8355.

Zhao, C., Zayed, O., Zeng, F., Liu, C., Zhang, L., Zhu, P., Hsu, C.C., Tuncil, Y.E., Tao, W.A., Carpita, N.C. \& Zhu, J.K. (2019) Arabinose biosynthesis is critical for salt stress tolerance in Arabidopsis. New Phytologist, 224, 274-290. 


\section{FIGURE LEGENDS}

Figure 1. Phenotype of maize seedlings and plants and chemical characterization of cell walls affected by salt stress. (A) Representative images of seedlings and plants indicating the suppression of growth under $200 \mathrm{mM} \mathrm{NaCl}$ conditions. Scale bar $=5 \mathrm{~cm}$. (B) Principal component analysis (PCA) of baseline corrected and peak normalized FTIR spectra and (C) loading plots of PC1 and PC2 from the PCA ( $n=3$ biological replicates). (D) Cellulose, matrix polysaccharides and lignin contents expressed as percentage of control plants. (E-H) Noncellulosic monosaccharide composition of alcohol insoluble residue (AIR). Xyl, xylose; Ara, arabinose; Glc, glucose; Gal, galactose; Man, mannose; Fuc, fucose; Rha, rhamnose; GlcA, glucuronic acid; GalA, galacturonic acid; S-Root, seedling root; Error bars represent SEM, $n=$ 7 biological replicates. $* 0.05 \geq P>0.01$, ** $0.01 \geq P>0.001$, and $* * * P \leq 0.001$, unpaired two-sided $t$-test.

Figure 2. Cell walls of seedling roots and plant roots exhibit reduced arabinoxylan content in response to salinity. (A) Xylose and arabinose amounts in the $1 \mathrm{M} \mathrm{KOH}$ and $4 \mathrm{M} \mathrm{KOH}$ cell wall fractions of seedling roots (S-roots) and plant roots during exposition to $200 \mathrm{mM} \mathrm{NaCl}$. Error bars represent SEM. $* 0.05 \geq P>0.01, * * 0.01 \geq P>0.001$, and $* * * P \leq 0.001$, unpaired two-sided t-test. (B) SEC-MALS analysis of xylan chain length in $1 \mathrm{M} \mathrm{KOH}$ and $4 \mathrm{M} \mathrm{KOH}$ fractions ( $n=4$ biological replicates). Data shown are representative of the results obtained for all $\mathrm{KOH}$ extracts. 
Figure 3. Structural characterization of arabinoxylans from seedling roots and plant roots. (A) 2D- HSQC-NMR spectra of whole-cell walls showing anomeric carbons of noncellulosic polysaccharides (Xyl: $\quad \beta$-D-xylopyranoside; $\quad 2$-Ac-Xyl: $2-O$-acetyl- $\beta$-Dxylopyranoside; 3-Ac-Xyl: 3-O-acetyl- $\beta$-D-xylopyranoside; 2,3-Ac-Xyl: 2,3-di-O-acetyl- $\beta$-Dxylopyranoside; Ara: $\alpha$-L-arabinofuranoside; Glc: $\beta$-D-glucopyranoside; S: residual starch). The spectra were normalized to the same intensity of the DMSO signals, since the same DMSO volume and amount of sample were used in all cases. (B) Digestion of cell walls of seedling roots (S-roots) and plant roots with CjGH10A and NpGH11 analyzed by PACE. Ladder: xylose (X1) to xylohexose (X6). \# indicates background bands. Representative gel of three independent experiments is shown.

Figure 4. Modulation of cell wall ester-linked hydroxycinnamates in response to salt stress. (A,B) Total ester-linked FA and $p C A$. (C,D) FA and $p C A$ esterified to AX. (E,F) FA and $p$ CA esterified to lignin. AIR, alcohol insoluble residue; S-Root, seedling roots. Error bars represent SEM, $n=5$ biological replicates. $* 0.05 \geq P>0.01, * * 0.01 \geq P>0.001$, and $* * * P$ $\leq 0.001$, unpaired two-sided $t$-test.

Figure 5. Salt stress induces the biosynthesis and accumulation of ferulic acid. (A-E) Gene expression analysis using quantitative PCR with reverse transcription (RT-qPCR) ( $n=4$ biological replicates). (F-J) Enzyme activities ( $n=6$ biological replicates). (K) Soluble ferulate ( $n=6$ biological replicates). (L) Diagram showing the steps involved in ferulate biosynthesis. In red are the genes and enzymes evaluated in this study. Error bars represent SEM. * $0.05 \geq$ 
$P>0.01, * * 0.01 \geq P>0.001$, and $* * * P \leq 0.001$, unpaired two-sided $t$-test. 4CL, $p$ hydroxycinnamate-CoA ligase; $\mathrm{C3H}$, p-coumarate 3-hydroxylase; COMT, caffeate 3-Omethyltransferase; FAT, putative feruloyl-CoA transferase; FAE, feruloyl esterase; HCT, hydroxycinnamoyl-CoA: shikimate/quinate hydroxycinnamoyltransferase; $\mathrm{C}^{\prime} \mathrm{H}, p$-coumaroyl shikimate/quinate 3'-hydroxylase; CCoAOMT, caffeoyl-CoA 3-O-methyltransferase; CCR, cinnamoyl-CoA reductase; HCALDH, hydroxycinnamaldehyde dehydrogenase. FW, fresh weight; DW, dry weight.

Figure 6. Phenolic profiles of seedling roots and plant roots during salt exposure. (A) Principal component analysis (PCA) of the untargeted phenolic profiling using UHPLC-ESIQ-ToF-MS negative ion mode and (B) structures of metabolites differentially expressed upon salinity presented in Tables 1 and 2. Data represent eight biological replicates of pools of roots.

Figure 7. 2D-HSQC-NMR spectra $\left(\delta \mathrm{c} / \delta_{\mathrm{H}} 90-150 / 5.90-7.90\right)$ of whole-cell walls of maize tissues submitted to salt stress. The colors of the main lignin structures identified in the NMR spectra match those of the corresponding signals. The signal intensities corresponding to tricin in the framed areas are amplified at twice the intensity.

Figure 8. Metabolic map integrating lignin and ferulic acid biosynthesis with feruloylation in response to salt stress in maize. The differential modulation of genes, enzymes, metabolites and cell wall components are shown for seedling roots, plant roots, stems and leaves. The colors of the cells indicate the increased (red) or decreased (blue) parameter in the salt-stressed 
samples compared to respective controls. Arrows with dashed lines designate putative routes. PAL, L-phenylalanine ammonia-lyase; PTAL, bifunctional L-phenylalanine/ L-tyrosine ammonia-lyase; C4H, cinnamate 4-hydroxylase; C3H p-coumarate 3-hydroxylase; COMT, caffeate/5-hydroxyferulate 3-O-methyltransferase; 4CL, p-hydroxycinnamate-CoA ligase; FAT, putative feruloyl-CoA transferase; FAE, feruloyl esterase; PAT, putative $p$-coumaroyl-CoA transferase; HCT, hydroxycinnamoyl-CoA shikimate/quinate hydroxycinnamoyltransferase; C3'H, p-coumaroyl shikimate/quinate 3'-hydroxylase; CCoAOMT, caffeoyl-CoA 3-Omethyltransferase; CCR, cinnamoyl-CoA reductase; HCALDH, hydroxycinnamaldehyde dehydrogenase; F5'H, ferulate 5'-hydroxylase/coniferaldehyde 5'-hydroxylase; CAD, cinnamyl alcohol dehydrogenase; PMT, p-coumaroyl-CoA monolignol transferase. 


\section{TABLES}

Table 1. Differential phenolic compounds in seedling roots. Characterization of the compounds is based on MS/MS fragmentation spectra. Peak area is expressed in counts. $n=8$ biological replicates. RT, retention time. The detection limit was set at a peak intensity of 100 counts.

\begin{tabular}{lcccccc}
\hline Compound & $\mathbf{m} / \mathbf{z}$ & $\mathbf{R T}(\mathbf{m i n})$ & Control & NaCl & Fold & $\boldsymbol{P}(\boldsymbol{t}$ test) \\
\hline 4-O-Feruloyl quinic acid & 367.1031 & 6.58 & 423 & 3004 & 7.10 & $1.3 \mathrm{E}-04$ \\
3-O-Feruloyl quinic acid & 367.1032 & 4.60 & 2232 & 9779 & 4.38 & $1.9 \mathrm{E}-04$ \\
Sinapoyl hexose & 385.1137 & 5.40 & 4371 & 2089 & 0.48 & $2.6 \mathrm{E}-07$ \\
DIMBOA glucoside & 372.0931 & 5.81 & 17567 & 7909 & 0.45 & $1.1 \mathrm{E}-04$ \\
\hline Syringoyl sinapoyl hexose & 565.1553 & 5.81 & 1080 & 469 & 0.43 & $4.2 \mathrm{E}-04$ \\
DIMBOA glucoside & 372.0933 & 4.50 & 8520 & 3593 & 0.42 & $5.2 \mathrm{E}-05$ \\
Apigenin-6,8-C-dihexoside & 593.1502 & 5.90 & 1009 & 389 & 0.39 & $7.7 \mathrm{E}-04$ \\
Feruloyl hexose & 355.1032 & 5.21 & 6575 & 2216 & 0.34 & $3.8 \mathrm{E}-06$ \\
Tricin + hexuronic acid + pentose & 637.1398 & 10.77 & 514 & 170 & 0.33 & $1.5 \mathrm{E}-05$ \\
DIMBOA + hexose + hexose & 534.1456 & 5.62 & 2485 & 806 & 0.32 & $2.5 \mathrm{E}-05$ \\
Isorhamnetin hexoside & 623.1605 & 10.02 & 1658 & 313 & 0.19 & $1.0 \mathrm{E}-04$ \\
Vanilloyl hexose & 329.0873 & 3.07 & 2513 & 310 & 0.12 & $1.6 \mathrm{E}-11$ \\
\hline
\end{tabular}


Table 2. Differential phenolic compounds in plant roots. Characterization of the compounds is based on MS/MS fragmentation spectra. Peak area is expressed in counts. $n=8$ biological replicates. RT, retention time. The detection limit was set at a peak intensity of 100 counts.

\begin{tabular}{|c|c|c|c|c|c|c|}
\hline Compound & $m / \mathbf{z}$ & RT (min) & Control & $\mathrm{NaCl}$ & Fold & $P(t$ test $)$ \\
\hline Feruloyl hexose & 355.1032 & 5.21 & 86 & 628 & 7.34 & $4.2 \mathrm{E}-04$ \\
\hline 3-O-Feruloyl quinic acid & 367.1032 & 4.60 & 1000 & 6667 & 6.66 & $1.0 \mathrm{E}-04$ \\
\hline DIMBOA glucoside & 372.0933 & 4.50 & 644 & 2793 & 4.34 & $1.4 \mathrm{E}-07$ \\
\hline Sinapoyl hexose & 385.1137 & 5.40 & 412 & 1625 & 3.94 & 2.8E-05 \\
\hline 4-O-Feruloyl quinic acid & 367.1031 & 6.58 & 354 & 1304 & 3.68 & 5.2E-04 \\
\hline Sinapoyl hexose + 226 kDa & 611.1966 & 7.99 & 223 & 788 & 3.53 & 2.4E-06 \\
\hline Sinapoyl hexose $+210 \mathrm{kDa}$ & 595.2023 & 9.25 & 1318 & 4517 & 3.43 & 4.7E-07 \\
\hline HBOA-2-O-hexoside & 326.0877 & 4.40 & 1393 & 636 & 0.46 & $9.8 \mathrm{E}-04$ \\
\hline Azelaic acid & 187.0973 & 10.79 & 764 & 244 & 0.32 & 2.8E-06 \\
\hline $\begin{array}{l}\text { 9,12,13-Trihydroxy-10(E)- } \\
\text { octadecadienoic acid }\end{array}$ & 329.2328 & 20.05 & 1140 & 324 & 0.28 & 4.2E-04 \\
\hline Hydroxybenzoic acid hexoside & 599.1603 & 1.79 & 1207 & 331 & 0.27 & 8.9E-05 \\
\hline $\begin{array}{l}\text { 9,12,13-Trihydroxy-10(E),15(Z)- } \\
\text { octadecadienoic acid }\end{array}$ & 327.2171 & 18.27 & 994 & 167 & 0.17 & $1.4 \mathrm{E}-04$ \\
\hline Trihydroxy-octadecadienoic acid & 329.2330 & 19.93 & 3852 & 613 & 0.16 & 1.7E-04 \\
\hline
\end{tabular}


Table 3. Lignin monomeric composition of control and salt-stressed maize tissues determined by alkaline nitrobenzene oxidation. AIR, alcohol insoluble residue; G, guaiacyl unit; S, syringyl unit. Values of difference indicate significantly increased or decreased percentage, as compared with those of respective control. $n=5-6$ biological replicates. $* 0.05 \geq P>0.01, * * 0.01 \geq P>0.001$, and $* * * P \leq 0.001$, unpaired two-sided $t$-test.

\begin{tabular}{|c|c|c|c|c|c|c|c|}
\hline Plant material & Treatment & $\begin{array}{l}\text { G } \\
\left(\mu g \mathrm{mg}^{-1} \mathrm{AIR}\right)\end{array}$ & $\begin{array}{l}S \\
\left(\mu g \mathrm{mg}^{-1} \mathrm{AIR}\right)\end{array}$ & $\begin{array}{l}\mathrm{G}+\mathrm{S} \\
\left(\mu \mathrm{g} \mathrm{mg}^{-1} \text { AIR) }\right.\end{array}$ & $\begin{array}{l}\text { G } \\
\text { (mol \%) }\end{array}$ & $\begin{array}{l}\text { S } \\
(\mathrm{mol} \%)\end{array}$ & $\mathrm{S} / \mathrm{G}$ ratio \\
\hline \multirow[t]{3}{*}{ Seedling roots } & Control & $4.27 \pm 0.14$ & $1.74 \pm 0.08$ & $6.01 \pm 0.08$ & $74.56 \pm 1.12$ & $25.44 \pm 1.12$ & $0.34 \pm 0.02$ \\
\hline & $\mathrm{NaCl}$ & $4.67 \pm 0.06$ & $2.99 \pm 0.10 * * *$ & $7.65 \pm 0.13^{* * *}$ & $65.23 \pm 0.82^{* * *}$ & $34.77 \pm 0.81^{* * *}$ & $0.53 \pm 0.02^{* * *}$ \\
\hline & Difference (\%) & 9 & 72 & 27 & -13 & 37 & 56 \\
\hline \multirow[t]{3}{*}{ Roots } & Control & $4.51 \pm 0.23$ & $2.29 \pm 0.14$ & $6.80 \pm 0.34$ & $70.29 \pm 0.81$ & $29.71 \pm 0.81$ & $0.42 \pm 0.02$ \\
\hline & $\mathrm{NaCl}$ & $7.78 \pm 0.30 * * *$ & $5.65 \pm 0.18^{* * *}$ & $13.43 \pm 0.42^{* * *}$ & $62.24 \pm 0.92^{* * *}$ & $37.76 \pm 0.92^{* * *}$ & $0.61 \pm 0.02^{* * *}$ \\
\hline & Difference (\%) & 72 & 147 & 97 & -11 & 27 & 45 \\
\hline \multirow[t]{3}{*}{$\mathrm{S} e \mathrm{~ms}$} & Control & $5.65 \pm 0.15$ & $2.93 \pm 0.04$ & $8.58 \pm 0.16$ & $69.76 \pm 0.61$ & $30.24 \pm 0.62$ & $0.43 \pm 0.01$ \\
\hline & $\mathrm{NaCl}$ & $6.31 \pm 0.32 *$ & $3.63 \pm 0.09 * * *$ & $9.94 \pm 0.27^{* *}$ & $67.33 \pm 1.45$ & $32.67 \pm 1.45$ & $0.48 \pm 0.03$ \\
\hline & Difference (\%) & 12 & 24 & 16 & -3 & 8 & 12 \\
\hline \multirow[t]{3}{*}{ _eaves } & Control & $2.81 \pm 0.21$ & $0.80 \pm 0.04$ & $3.61 \pm 0.22$ & $80.51 \pm 1.60$ & $19.49 \pm 1.60$ & $0.24 \pm 0.01$ \\
\hline & $\mathrm{NaCl}$ & $3.02 \pm 0.19$ & $0.97 \pm 0.06 *$ & $3.98 \pm 0.25$ & $78.84 \pm 0.54$ & $21.16 \pm 0.53$ & $0.27 \pm 0.04$ \\
\hline & Difference (\%) & 7 & 21 & 6 & -2 & 9 & 13 \\
\hline
\end{tabular}


Table 4. Summary of the main alterations of cell wall composition and phenolic metabolites in response to salinity. $\uparrow$ indicates increased parameter, $\downarrow$ indicates decreased parameter and $=$ indicates no significant difference in the salt-stressed samples compared to respective controls. nd, not detected or not determined.

\begin{tabular}{|c|c|c|c|c|}
\hline \multirow[t]{2}{*}{ Parameter } & \multirow{2}{*}{$\begin{array}{c}\text { Seedlings } \\
\text { Roots }\end{array}$} & \multicolumn{3}{|c|}{ Plants } \\
\hline & & Roots & Stems & Leaves \\
\hline Cellulose & $=$ & $\downarrow$ & $\uparrow$ & $=$ \\
\hline Matrix polysaccharides & $\downarrow$ & $\downarrow$ & $=$ & $\uparrow$ \\
\hline Xylose & $\downarrow$ & $\downarrow$ & $=$ & $=$ \\
\hline Arabinose & $\downarrow$ & $\downarrow$ & $=$ & $\uparrow$ \\
\hline Glucose & $\downarrow$ & $=$ & $\uparrow$ & $\uparrow$ \\
\hline Arabinoxylan (AX) & $\downarrow$ & $\downarrow$ & nd & nd \\
\hline Xylose & $\downarrow$ & $\downarrow$ & nd & nd \\
\hline Arabinose & $\downarrow$ & $\downarrow$ & nd & nd \\
\hline AX by SEC-MALS (Abundance) & $\downarrow$ & $\downarrow$ & nd & nd \\
\hline AX by SEC-MALS (Chain length) & $=$ & $=$ & nd & nd \\
\hline AX by NMR & $\downarrow$ & $\downarrow$ & nd & nd \\
\hline AX by PACE & $=$ & $=$ & nd & nd \\
\hline Total ester-linked FA & $\downarrow$ & $\downarrow$ & $\uparrow$ & $=$ \\
\hline Ester-linked FA to AX & $\downarrow$ & $\downarrow$ & $\uparrow$ & $=$ \\
\hline Ester-linked FA to lignin & $=$ & $=$ & $=$ & $=$ \\
\hline Total ester-linked $p C A$ & $\downarrow$ & $=$ & $\downarrow$ & $=$ \\
\hline Ester-linked $p \mathrm{CA}$ to $\mathrm{AX}$ & $\downarrow$ & $=$ & $=$ & $=$ \\
\hline Ester-linked $p C A$ to lignin & $\downarrow$ & $=$ & $\downarrow$ & $=$ \\
\hline \multicolumn{5}{|l|}{ Gene expression } \\
\hline$R F 2 C$ & $=$ & $\uparrow$ & $=$ & $=$ \\
\hline$R F 2 D$ & $=$ & $\uparrow$ & $=$ & $=$ \\
\hline COMT1 & $\uparrow$ & $\uparrow$ & $\downarrow$ & $\downarrow$ \\
\hline ССОАОМТ1 & $\downarrow$ & $\uparrow$ & $\uparrow$ & $\uparrow$ \\
\hline ССОАОМТ1 & $\downarrow$ & $\uparrow$ & $=$ & $\downarrow$ \\
\hline \multicolumn{5}{|l|}{ Enzyme activity } \\
\hline 4CL (pCA) & $\downarrow$ & $\downarrow$ & $\downarrow$ & $=$ \\
\hline 4CL (FA) & $\downarrow$ & $\downarrow$ & $\uparrow$ & $=$ \\
\hline HCALDH & $\uparrow$ & $\uparrow$ & $\uparrow$ & $=$ \\
\hline COMT & $=$ & $\uparrow$ & $\uparrow$ & $=$ \\
\hline FAE & $\uparrow$ & $\uparrow$ & $\downarrow$ & $=$ \\
\hline Lignin content & $\uparrow$ & $\uparrow$ & $\uparrow$ & $=$ \\
\hline \multicolumn{5}{|l|}{ Lignin composition (mol \%) } \\
\hline G-unit by nitrobenzene oxidation & $\downarrow$ & $\downarrow$ & $=$ & $=$ \\
\hline G-unit by NMR & $\downarrow$ & $\downarrow$ & $=$ & $\downarrow$ \\
\hline S-unit by nitrobenzene oxidation & $\uparrow$ & $\uparrow$ & $=$ & $=$ \\
\hline S-unit by NMR & $\uparrow$ & $\uparrow$ & $=$ & $\uparrow$ \\
\hline $\mathrm{S} / \mathrm{G}$ ratio nitrobenzene oxidation & $\uparrow$ & $\uparrow$ & $\uparrow$ & $=$ \\
\hline S/G ratio by NMR & $\uparrow$ & $\uparrow$ & $\uparrow$ & $\uparrow$ \\
\hline Tricin by NMR & nd & nd & $=$ & $=$ \\
\hline
\end{tabular}

Phenolic metabolites 
FA

3-O-Feruloyl quinic acid

4-O-Feruloyl quinic acid

\begin{tabular}{cccc}
$\uparrow$ & $\uparrow$ & $\uparrow$ & $\downarrow$ \\
$\uparrow$ & $\uparrow$ & nd & nd \\
$\uparrow$ & $\uparrow$ & nd & nd \\
\hline
\end{tabular}

This article is protected by copyright. All rights reserved. 
Control

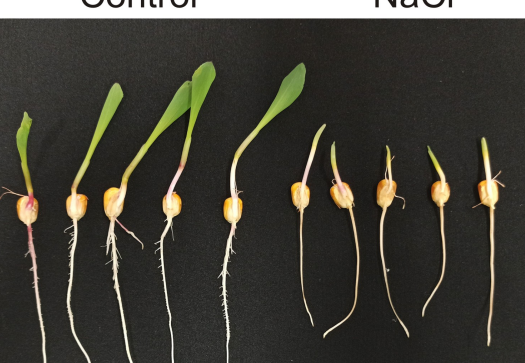

(1)

C

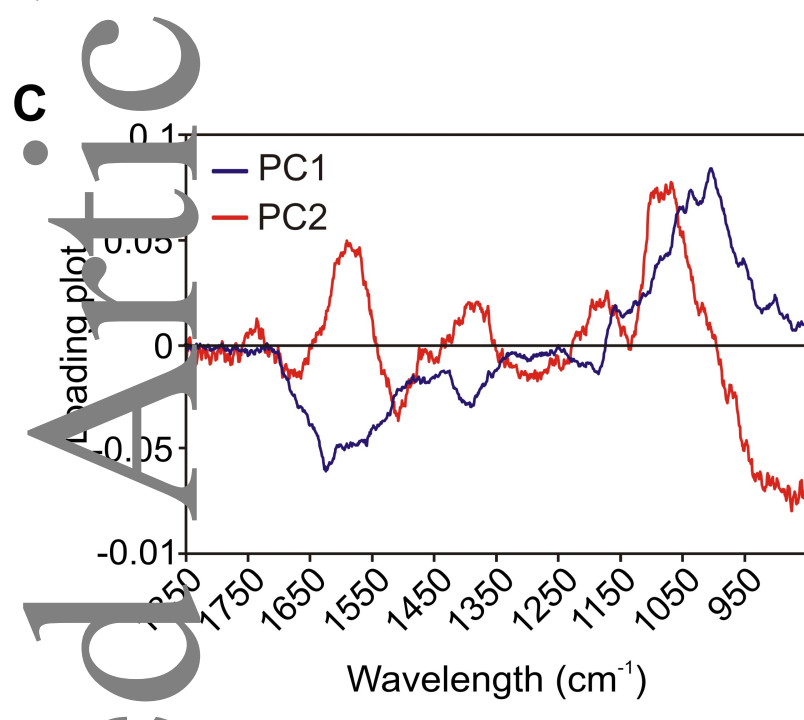

E
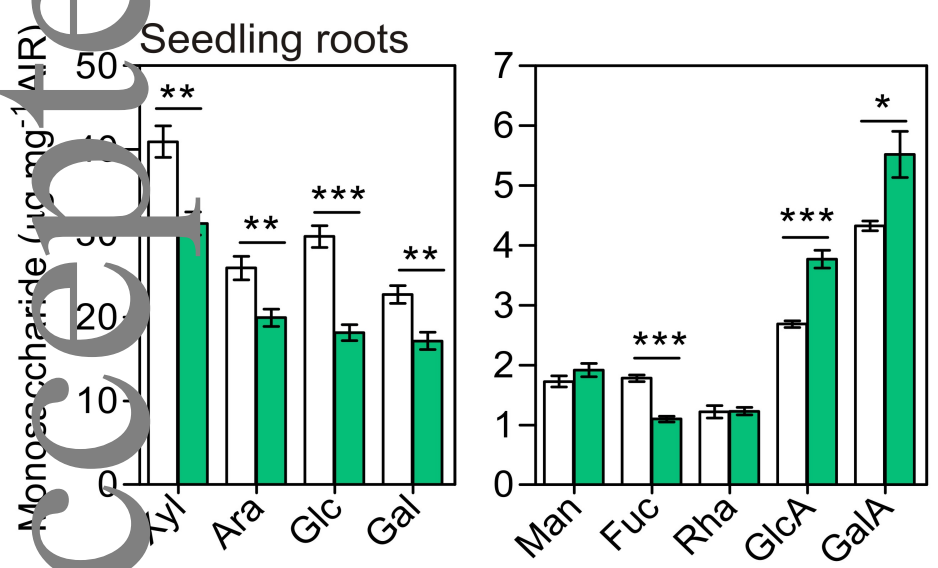

(1)
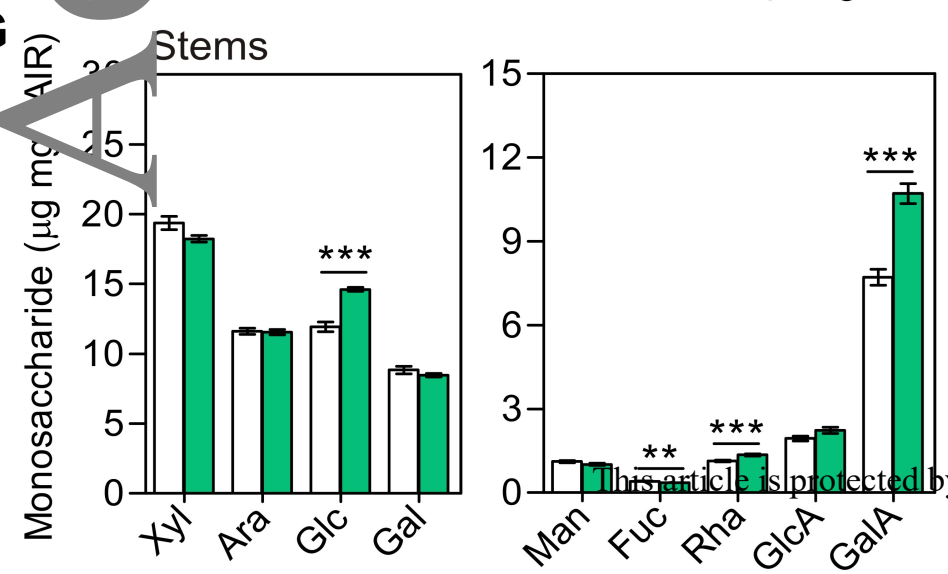

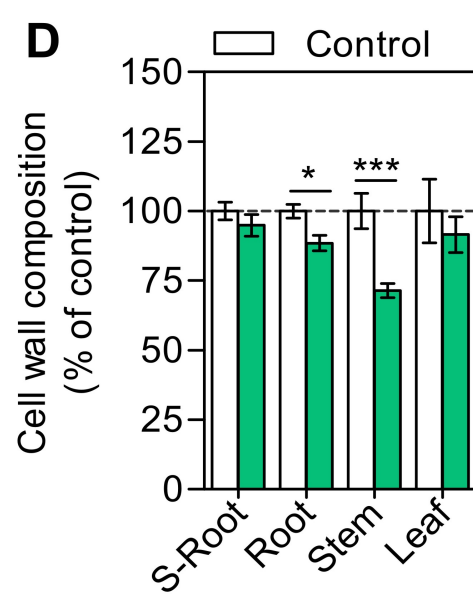

Cellulose

$F$
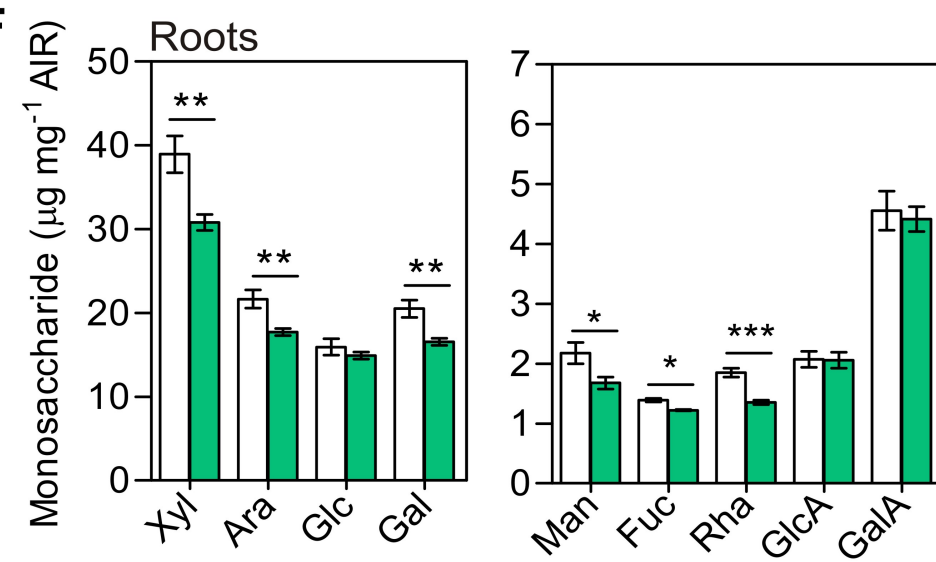

H

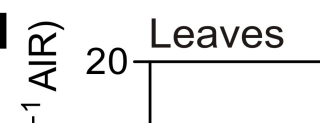

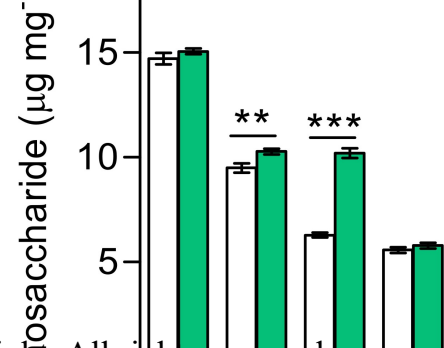

$\sum^{0}+r^{2} r^{2} \sigma^{c} 0^{2}$
O Stems $\mathrm{NaCl}$

oStems Control Roots Control O

O Roots $\mathrm{NaCl}$

O S-Roots Control

o S-Roots $\mathrm{NaCl}$

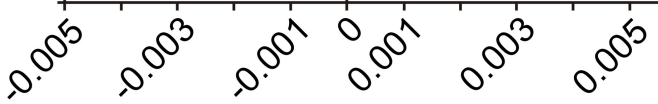
PC1 (67\%) 
Seedling roots

Roots

B

$1 \mathrm{M} \mathrm{KOH}$ Fraction
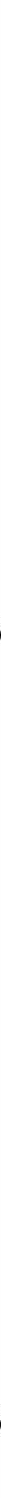
A jeedling roots

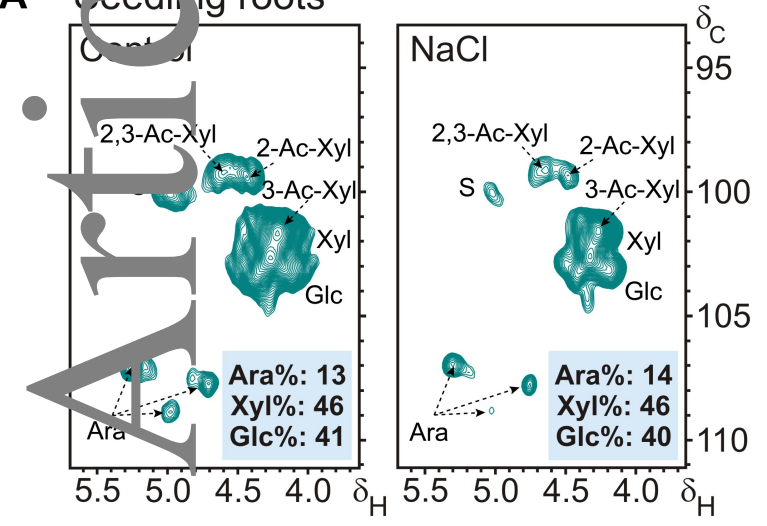

Roots

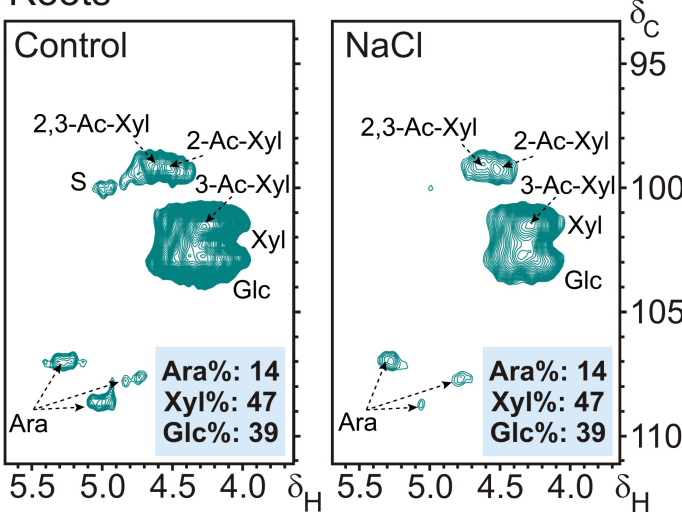

B $($ cjGH 0 A digestion

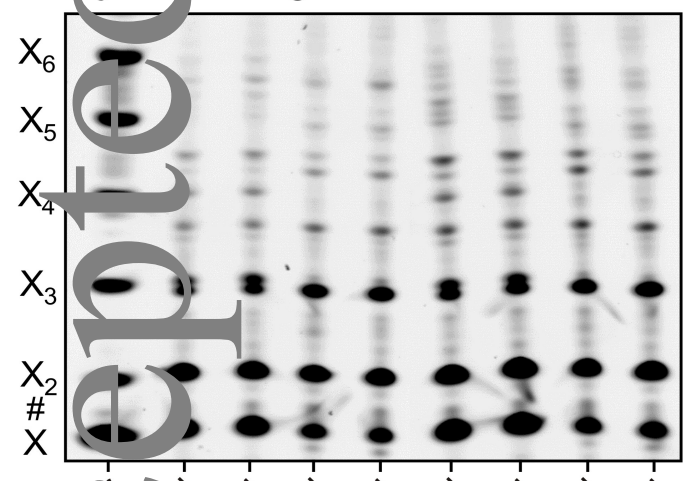

NpGH11 digestion

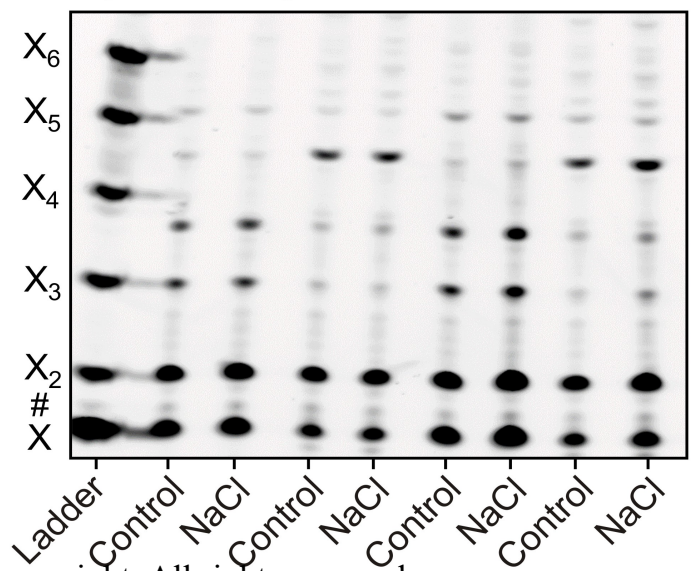

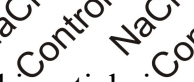

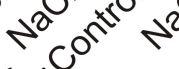

This article is protected

GH 2 GH115 GH62 GH115

dling roots

Roots
All rights reserved.

GH62 GH115 GH62 GH115

Seedling roots

Roots 


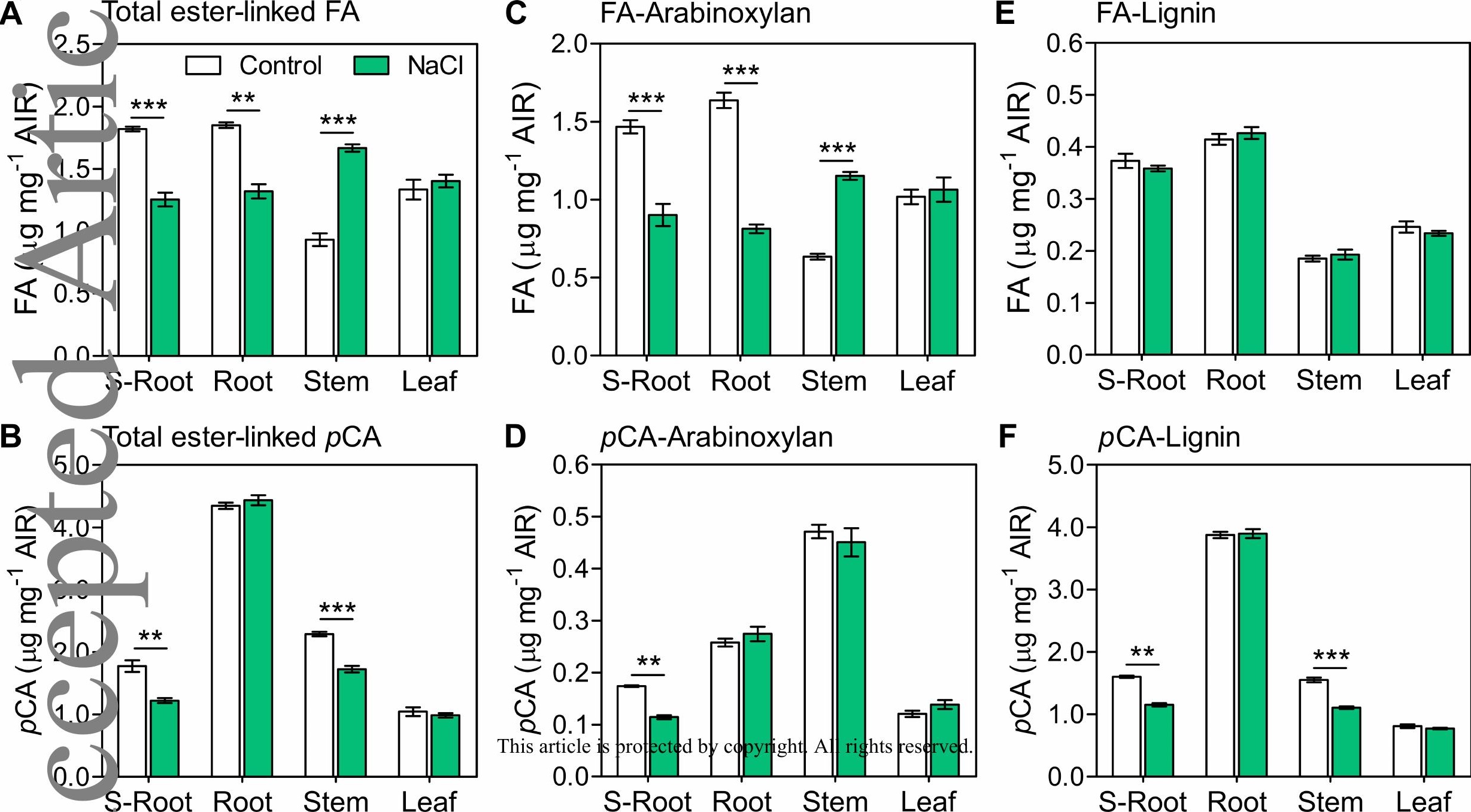




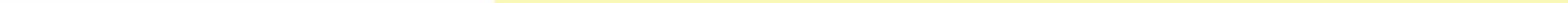




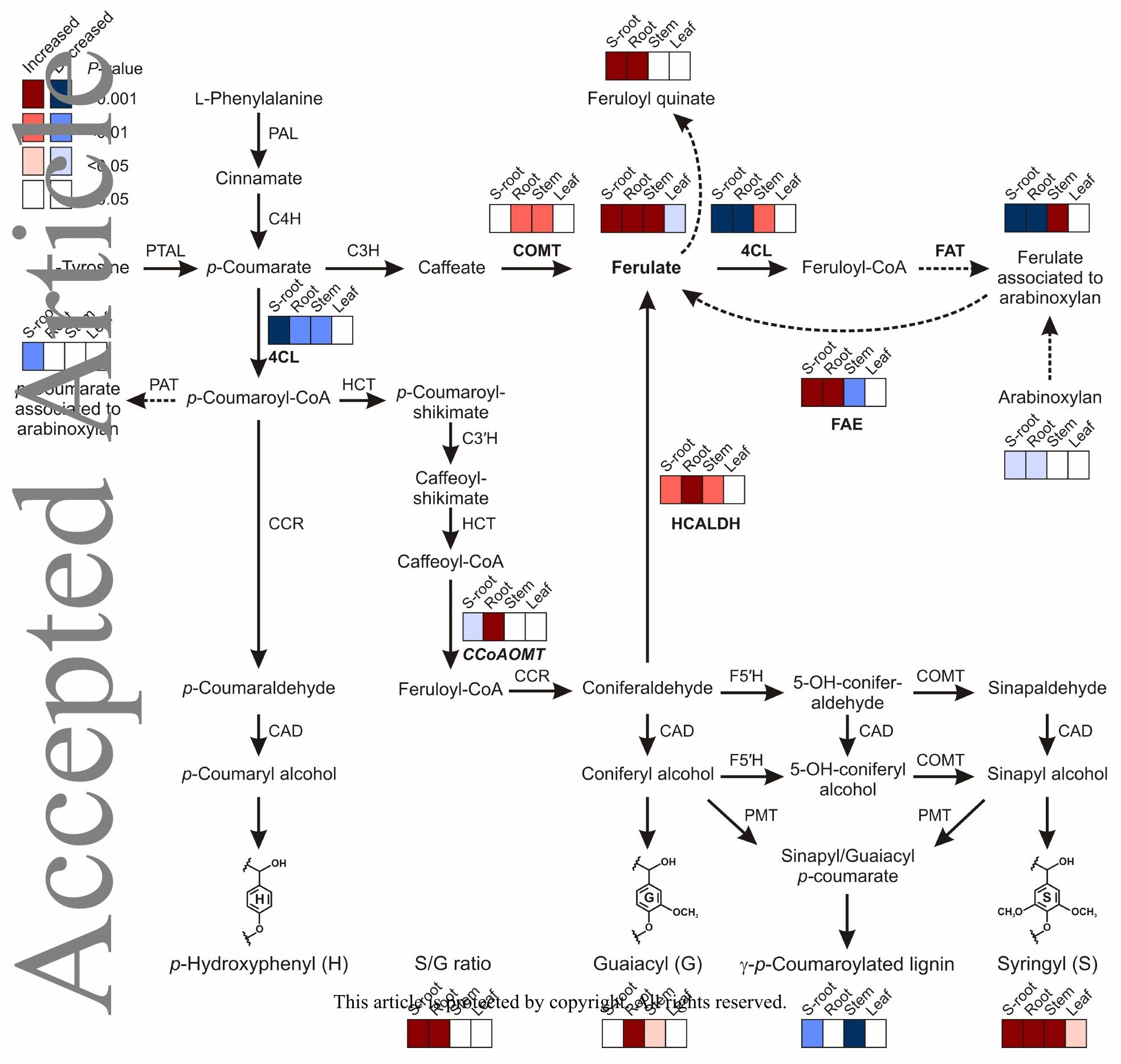

